\title{
Wind load analysis of tall chimneys with piled raft foundation considering the flexibility of soil
}

\author{
B. R. Jayalekshmi ${ }^{1} \cdot$ S. V. Jisha ${ }^{1} \cdot$ R. Shivashankar ${ }^{1}$
}

Received: 30 January 2014/ Accepted: 30 March 2015/Published online: 15 April 2015

(c) The Author(s) 2015. This article is published with open access at Springerlink.com

\begin{abstract}
Soil-structure interaction (SSI) analysis was carried out for tall reinforced concrete chimneys with piled raft foundation subjected to wind loads. To understand the significance of SSI, four types of soil were considered based on different material properties. Chimneys of different elevations and different ratios of height to base diameter of chimney were selected for the parametric study. The thickness of raft of piled raft foundation was also varied based on different ratios of outer diameter to thickness of raft. The chimneys were assumed to be located in open terrain and subjected to a maximum wind speed of $50 \mathrm{~m} / \mathrm{s}$. The along-wind and across-wind loads were computed according to IS: 4998 (Part 1)-1992 and applied along the height of the chimney. The analysis was carried out using three-dimensional finite element technique based on the direct method of SSI. The linear elastic material behaviour was assumed for the integrated chimney-foundation-soil system. The radial and tangential moments, lateral deflection and base moment of chimney were evaluated through SSI analysis and compared with the response obtained from chimney with fixed base. The base moment of chimney considerably reduces due to the effect of SSI. It is found that the variation of different responses in chimney due to the effect of SSI depends significantly on the geometrical properties of chimney and foundations.
\end{abstract}

S. V. Jisha

jpn.nitk@gmail.com

B. R. Jayalekshmi

br.jaya@gmail.com

R. Shivashankar

shivashankar.surathkal@gmail.com

1 National Institute of Technology Karnataka, Surathkal, Karnataka, India

The response variation at base for a distance of 1/40th of the height of chimney should be considered for a safe design.

Keywords Piled raft foundation - Reinforced concrete chimney $\cdot$ Soil-structure interaction $\cdot$ Wind load

\section{Lists of symbols}

B

$C_{\mathrm{D}}$

$C_{\mathrm{L}}$

$\bar{C}_{\mathrm{L}}$

$D_{\mathrm{b}}$

$D_{\mathrm{t}}$

$T_{\mathrm{b}}$

$T_{\mathrm{t}}$

$D_{\mathrm{o}}$

$D_{\mathrm{i}}$

$d_{z}$

$d$

E

$E_{\mathrm{R}}$

$E_{\mathrm{S}}$

EI

$F_{z i}$

$F_{z m}$

$F_{z o i}$

$f_{i}$

G
Background factor indicating the slowly varying component of wind load fluctuation Drag co-efficient of chimney

Peak oscillatory lift coefficient

RMS lift coefficient

Diameter at bottom of the chimney

Diameter at top of the chimney

Thickness at base of the chimney shell

Thickness at top of the chimney shell

Outer diameter of annular raft

Inner diameter of annular raft

Diameter of chimney at height $z$

Effective diameter taken as average diameter over the top $1 / 3$ rd height of the chimney A measure of the available energy in the wind at the natural frequency of chimney Young's modulus of raft Young's modulus of soil Bending stiffness of chimney

The wind load in $\mathrm{N} / \mathrm{m}$ height due to the fluctuating component of wind at height $z$ Wind load in $\mathrm{N} / \mathrm{m}$ height due to hourly mean wind speed at height $z$

Sectional shear force $i$ th mode of vibration Natural frequency of chimney in the $i$ th mode of vibration

Gust factor 
$g_{\mathrm{f}} \quad$ Peak factor defined as the ratio of the expected peak value to RMS value of the fluctuating load

$H \quad$ Total height of the chimney

$K_{s i} \quad$ Mass damping parameter for the $i$ th mode of vibration

$k_{\mathrm{a}} \quad$ Aerodynamic damping co-efficient

$K_{\mathrm{CS}} \quad$ Relative stiffness of chimney

$K_{\mathrm{RS}} \quad$ Relative stiffness of raft

$L \quad$ Correlation length

$M_{\text {(base) }} \quad$ Base moment of chimney with fixed base

$m_{e i} \quad$ Equivalent mass per unit length in $\mathrm{kg} / \mathrm{m}$ in the $i$ th mode of vibration

$m_{z} \quad$ Mass per unit length of the chimney at section $z$ in $\mathrm{kg} / \mathrm{m}$

$M_{z o i} \quad$ Bending moment $i$ th mode of vibration

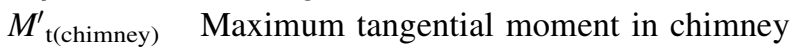
with flexible base

$M_{\mathrm{t}(\mathrm{chimney})} \quad$ Maximum tangential moment in chimney with fixed base

$M_{\text {r(chimney) }}^{\prime}$ Maximum radial moment in chimney with flexible base

$M_{\text {r(chimney) }} \quad$ Maximum radial moment in chimney with fixed base

$p_{z} \quad$ Design wind pressure in $\mathrm{N} / \mathrm{m}^{2}$ at height $z$

$\bar{p}_{z} \quad$ Design pressure at height $z$ due to hourly mean wind speed

Twice the turbulence intensity

Size reduction factor

$S$

$\mathrm{S}_{n}$

$t, t_{\mathrm{R}}$

$\bar{V}_{z}$

X

$z$

$\alpha$

$\beta$

$\eta_{o i}$

$\cap$

$\phi_{z i}$

$\delta_{\mathrm{s}}$

$\sigma$

$\Delta^{\prime}$

$\Delta$

$\gamma_{\mathrm{c}}$

$\gamma_{\mathrm{s}}$

$v_{\mathrm{S}}$

$v_{\mathrm{S}}$

Strouhal number

Thickness of the raft

Hourly mean wind speed

Modification factor

Height of any section of chimney from top of foundation

Power law exponent

Coefficient of damping of the structure

Peak tip deflection due to vortex shedding in the $i$ th mode of vibration

Equivalent aspect ratio

Mode shape function normalized with respect to the dynamic amplitude at top of the chimney in the $i$ th mode of vibration

Logarithmic decrement of structural damping Mass density of air

Tip deflection of chimney with flexible base Tip deflection of chimney with fixed base

Density of material of chimney-foundation system

Density of soil stratum

Poisson's ratio of raft

Poisson's ratio of soil

\section{Introduction}

Chimneys are very important structures in any industry and are used to discharge the pollutants to higher atmosphere. The chimney elevations have gone up progressively from $100 \mathrm{~m}$ to more than $400 \mathrm{~m}$ due to the high demand of pollution control. Chimneys have unique geometrical features of slender dimensions and tapering geometry and, therefore, the analysis and design of such kind of structure should be treated separately from other forms of tower structures. These tall chimneys are very sensitive to wind loads.

The dynamic wind effects on chimney are predicted by analytical procedures but they are somewhat complicated, time-consuming and require specialized software. If the modes of chimney are well separated then simplified design procedures can be used. The simplified design techniques such as static or quasi-static methods that account for the wind effect of chimney were given by Manohar (1985). The effect of wind on such tall freestanding structures has two components, namely along-wind and across-wind load conditions. The chimney is subjected to gust buffeting in the along-wind direction (due to drag forces), and also to possible vortex shedding in the across-wind direction. The along-wind and across-wind loads can be estimated using most of the design codes for chimneys (CICIND 2001; ACI 307-08 2008; Koten 2005; IS: 4998(Part 1)-1992 2003). The gust factor method (Davenport 1967) is one of the prominent methods widely used for the along-wind load calculation and various modifications have been made on gust factor method by many researchers (Simiu 1976; Solari 1982). The international codal recommendations were reviewed by Menon and Rao (1997a, b) to determine the design moments for along-wind and across-wind load conditions in reinforced concrete chimneys. Different expressions were formulated by several researchers (Vickery and Clark 1972; Kwok and Melbourne 1981; Davenport 1995; Melbourne 1997) to evaluate the response of structures due to across-wind load conditions. An empirical method was presented by Arunachalam et al. (2001) for correlating the rms lift coefficient due to vortex shedding and Strouhal number. The above studies neglect the effect of foundation and underlying soil.

The annular raft foundations are more reasonable and economical than the full circular raft for industrial chimneys. If the geotechnical conditions are not favourable for raft foundations, piled foundations can also be used. Skin friction piles are more suitable to chimney foundations than end bearing piles, since greater uplift capacity is generally available (Turner 2005). It is seen that generally the analysis of these foundations is carried out without considering the effect of super structure (Chu and Afandi 1966; Brown 
1969; Melerski 1990; IS: 11089-1984 2002; Dewaikar and Patil 2006). Chaudhary (2007) investigated the effectiveness of pile foundation in reducing settlement by comparing the results of piled raft foundation and the raft foundation alone. Analysis of foundation without structure and analysis of structure without foundation may give incorrect results in the different responses of structure and foundation.

Studies by Pour and Chowdhury (2008) proved that base moment of tall chimney founded on soft soil increase up to $10 \%$ due to along-wind load and decrease up to $50 \%$ due to across-wind load that may affect the design forces. The effect of long-duration earthquakes as well as the higher mode participation in a 215-m tall chimney considering SSI is studied by Mehta and Gandhi (2008). Considerable reduction in the bending moments in the annular raft foundation of tall chimneys due to the effect of flexibility of supporting soil under along-wind load is reported (Jayalekshmi et al. 2011). The above studies point towards the need of further investigation on the SSI analysis of chimneys with piled raft foundations.

\section{Soil-structure interaction}

The response of the structure affects the motion of supporting soil and the movement of supporting soil influences the structural behaviour. This inter-dependency of response between the structure and the soil is referred as SSI. Depending on the modelling method for the soil stratum, all the SSI problems can be classified into two main categories, namely direct method and substructure method (Wolf 1985). The direct method evaluates the response of structure and its surrounding soil in a single analysis step by subjecting the combined soil-structure system to applied loads. The finite element analysis can be easily implemented in this method of SSI. In substructure approach, the soil-structure system is divided into two or more substructures. Each substructure is modelled independently and the general structure is formed by connecting these individual substructures through the interface of adjacent or other substructures. The substructure method is based on the principle of superposition.

The two most common soil models which are generally used for soil-structure interaction problems are winkler spring model and finite element models of an elastic continuum. In winkler spring method, soil medium is assumed to consist of a series of closely spaced springs on which the foundation slab lies. The springs are linear in nature and are dependent on the subgrade modulus (Wolf 1985; Arya and Paul 1977; Bowles 1997). Elastic continuum model is a conceptual approach of physical representation of the infinite soil media (Rajasankar et al. 2007; Tabatabaiefar and
Massumi 2010; Cakir 2013). For the finite element model, the accuracy is valid to the extent of realistic estimate of the elastic modulus of the soil and Poisson's ratio (Chowdhury and Dasgupta 2009). Real progress in the area of three-dimensional soil-structure interaction has taken place with the advent of digital computers (Jayalekshmi et al. 2011; Rajasankar et al. 2007; Tabatabaiefar and Massumi 2010; Cakir 2013).

Only a few studies have been carried out on the SSI analysis of tall chimney structures under wind load compared to seismic load (Pour and Chowdhury 2008; Jayalekshmi et al. 2011). It is also found that limited research has been done in the area of SSI analysis of tall chimneys with piled raft foundation. In this parametric study, threedimensional SSI analysis of reinforced concrete chimneys with piled raft foundation subjected to wind loads was carried out using finite element method based on the direct method of SSI. The equivalent static wind loads were computed as per IS: 4998(Part 1)-1992 (2003). The linear elastic material behaviour of chimney, piled raft and the soil was assumed. Different responses in chimney such as lateral deflection, tangential moment, radial moment and base moment were evaluated incorporating SSI. These responses obtained from SSI analysis were compared with those obtained from the analysis of chimney with fixed base.

\section{Characteristics of structural and geotechnical model}

\section{Idealization of chimney}

Tall reinforced concrete chimneys of different elevations and base diameters were considered for the present study. Practical range of ratio of height to base diameter (slenderness ratio) of chimneys varies from 7 to 17 (Menon and Rao 1997a). The chimney elevations of 100, 200, 300 and $400 \mathrm{~m}$ were selected with slenderness ratios $\left(H / D_{\mathrm{b}}\right)$ of 7 , 12 and 17. The taper ratio (ratio of top diameter to base diameter) and ratio of base diameter to thickness at bottom were considered as 0.6 and 35 , respectively. The thickness at top of chimney was taken as 0.4 times the thickness at bottom but the minimum thickness at top was kept as $0.2 \mathrm{~m}$. All the above geometric parameters of chimney were selected based on the study conducted by Menon and Rao (1997a). Details of different geometric parameters of chimney are given in Table 1. Linear elastic material behaviour of chimney was assumed in the study. M30 grade concrete and Fe 415 grade steel were selected as the materials for chimney. The modulus of elasticity for chimney was taken as 33.5 Gpa as per IS: 4998(Part 1)-1992 (2003). The Poisson's ratio and density of concrete were taken as 0.15 and $25 \mathrm{kN} / \mathrm{m}^{3}$, respectively, for chimney. 


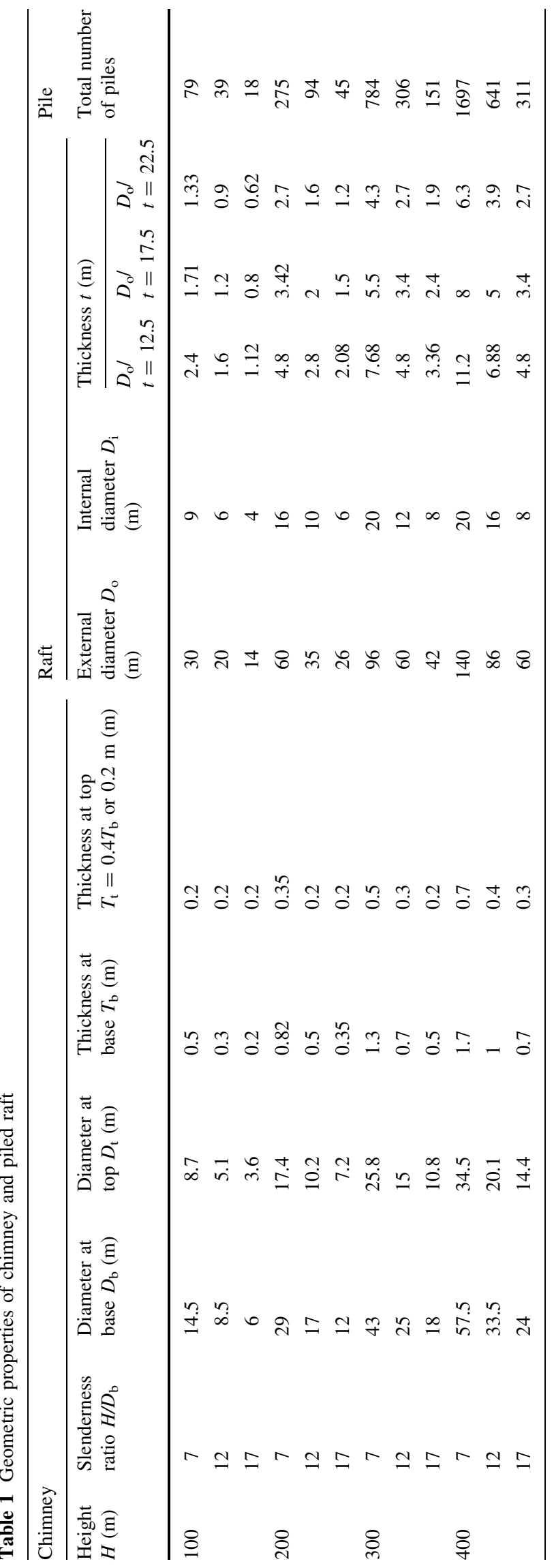

\section{Idealization of piled raft foundation}

Tall chimneys supported over piled raft foundation were considered. The raft of piled raft foundation was considered as annular with uniform thickness. The overall diameter of raft for a concrete chimney is typically $50 \%$ greater than the diameter of the chimney shaft at ground level (Turner 2005). The ratio of outer diameter to thickness $\left(D_{\mathrm{o}} / t\right)$ of annular raft was taken as 12.5, 17.5 and 22.5 (Jayalekshmi et al. 2011). RC friction piles of $20 \mathrm{~m}$ length $(l)$ and $1 \mathrm{~m}$ diameter were considered. For friction piles, the optimum spacing recommended is $3 d$ where $d$ is the diameter of the pile. Spacing $(s)$ of $3 d$ ensures that interference of stress zones of adjacent friction piles is minimum and results in a high group efficiency. Therefore, $s / d$ of 3 was selected for the present study. Table 1 gives the details of different geometric parameters of raft and the total number of piles. Figure 1 shows the plan view of raft of piled raft foundation of $200 \mathrm{~m}$ chimney $\left(H / D_{\mathrm{b}}=12\right)$. The linear elastic material behaviour was considered for piled raft foundation. The modulus of elasticity of 27.39 Gpa was calculated corresponding to M30 grade concrete using the equation, $E_{\mathrm{c}}=$ $5000 \sqrt{f c k}$ as there is no IS code that provides the modulus values for piled raft foundation directly. Grade of steel was selected as Fe 415. The Poisson's ratio for piled raft foundation was taken as 0.15 and density of concrete were taken as $25 \mathrm{kN} / \mathrm{m}^{3}$.

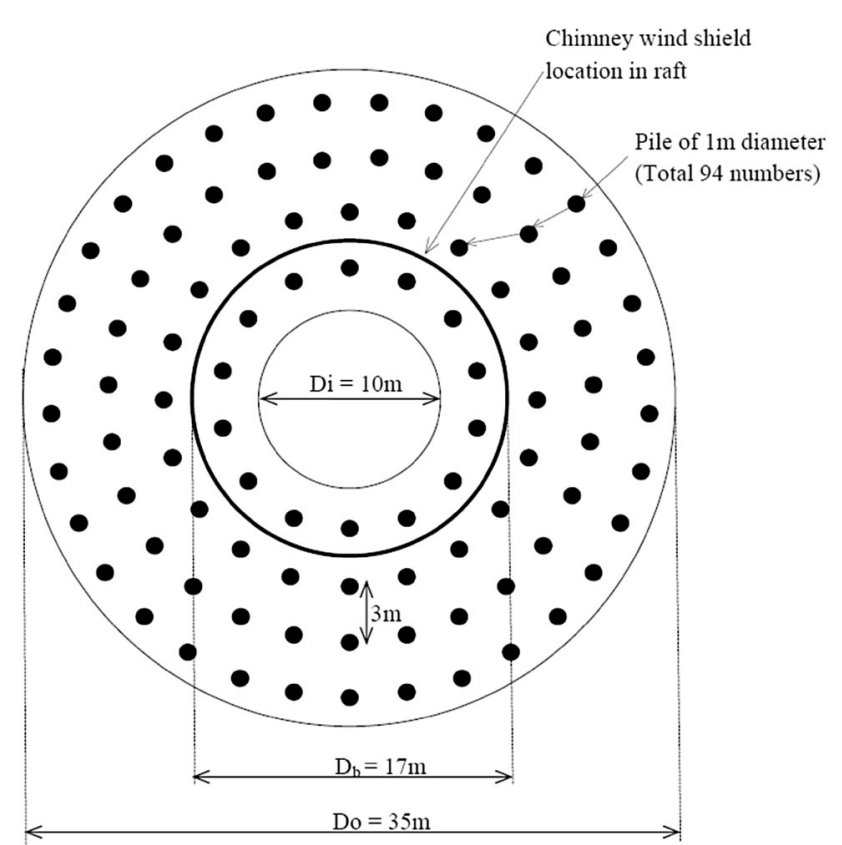

Fig. 1 Plan view of piled raft foundation of $200 \mathrm{~m}$ chimney (H/ $\left.D_{\mathrm{b}}=12\right)$ 


\section{Idealization of soil stratum}

The soil is idealized by single homogeneous strata of $30 \mathrm{~m}$ depth beneath the foundation. The bedrock was assumed to be at a depth of $30 \mathrm{~m}$ for all chimneys. Wolf (1985) stated that the boundary of the soil should be placed at a sufficient distance from the structure where the static response has died out. Previous studies of SSI effect (Ghosh and Wilson 1969; Rajasankar et al. 2007; Tabatabaiefar and Massumi 2010; Sáez et al. 2011) considered the width of soil as 3-4 times the width of the foundation. In this study, the lateral boundary of soil was placed at a distance of four times the width of foundation. To study the effect of SSI, the properties of the soil stratum were varied. For this, four types of dry cohesionless soil, S1, S2, S3 and S4, were selected, which represent loose sand, medium sand, dense sand and rock, respectively. The properties of the soil stratum were defined by its mass density, elastic modulus and Poisson's ratio as per the references (Bowles 1997; NEHRP 1994). Coefficient of internal friction between the soil and the pile were taken as per Meyerhof from the foundation engineering book (Fang 1991). The properties of the soil stratum are given in Table 2.

\section{Estimation of along-wind and across-wind load as per IS: 4998 (Part 1)-1992}

There are two methods for estimating along-wind and across-wind loads for chimneys as per IS: 4998(Part 1)-1992 (2003): simplified method and random response method. The chimneys are classified as class $\mathrm{C}$ structures located in terrain category 2 and subjected to a basic wind speed of $50 \mathrm{~m} / \mathrm{s}$. According to IS: 875(Part 3)-1987 (2003), terrain category 2 is an open terrain with well-scattered obstructions having heights generally between 1.5 and $10 \mathrm{~m}$.

\section{Along-wind load}

\section{Simplified method}

The along-wind load or drag force per unit height $(\mathrm{N} / \mathrm{m})$ of the chimney at any level is calculated using the following equation:

Table 2 Properties of the soil types

\begin{tabular}{lllll}
\hline $\begin{array}{l}\text { Soil } \\
\text { type }\end{array}$ & $\begin{array}{l}\text { Elastic modulus, } \\
E\left(\mathrm{kN} / \mathrm{m}^{2}\right)\end{array}$ & $\begin{array}{l}\text { Poisson's } \\
\text { ratio, } v\end{array}$ & $\begin{array}{l}\text { Unit weight, } \\
\gamma\left(\mathrm{kN} / \mathrm{m}^{3}\right)\end{array}$ & $\begin{array}{l}\text { Angle of } \\
\text { friction }\left(^{\circ}\right)\end{array}$ \\
\hline S1 & 108,000 & 0.4 & 16 & 30 \\
S2 & 446,000 & 0.35 & 18 & 35 \\
S3 & $1,910,000$ & 0.3 & 20 & 40 \\
S4 & $7,630,000$ & 0.3 & 20 & 45 \\
\hline
\end{tabular}

$F_{z}=p_{z} C_{\mathrm{D}} d_{z}$

where $p_{z}$ is the design wind pressure in $\mathrm{N} / \mathrm{m}^{2}$ at height $\mathrm{z}$, $z$ is the height of any section of chimney from top of foundation in $\mathrm{m}, C_{\mathrm{D}}$ is the 0.8 , drag co-efficient of chimney and $d_{z}$ is the diameter of chimney at height $z$ in $\mathrm{m}$

\section{Random response method}

The along-wind load per unit height at any height $z$ on a chimney is calculated using the following equation:

$F_{z}=F_{z m}+F_{z i}$,

where $F_{z m}$ is the wind load in $\mathrm{N} / \mathrm{m}$ height due to hourly mean wind (HMW) speed at height $z$ and $F_{z i}$ is the wind load in $\mathrm{N} / \mathrm{m}$ height due to the fluctuating component of wind at height $z$.

$F_{z m}=\bar{p}_{z} C_{\mathrm{D}} d_{z}$

where $\bar{p}_{z}$ is the design pressure at height $z\left(\mathrm{~N} / \mathrm{m}^{2}\right)$ due to HMW speed, $\bar{P}_{z}=0.6 \bar{V}_{z}^{2}$, where $\bar{V}_{z}$ is the HMW speed in $\mathrm{m} / \mathrm{s}$.

$F_{z i}=3 \frac{(G-1)}{H^{2}} \frac{z}{H} \int_{0}^{H} F_{z m} z \mathrm{~d} z$,

where $G$ is the gust factor which is calculated from the following equation:

$G=1+g_{\mathrm{f}} r \sqrt{B+\frac{S E}{\beta}}$,

where $g_{\mathrm{f}}$ is the peak factor defined as the ratio of the expected peak value to RMS value of the fluctuating load, $r$ is the twice the turbulence intensity, $B$ is the background factor indicating the slowly varying component of wind load fluctuation, $E$ is the measure of the available energy in the wind at the natural frequency of chimney, $S$ is the size reduction factor, $\beta$ is the coefficient of damping of the structure and $H$ is the total height of the chimney in $\mathrm{m}$.

\section{Across-wind load}

\section{Simplified method}

The amplitude of vortex excited oscillation perpendicular to direction of wind for any mode of oscillation shall be calculated by the following formula:

$\eta_{o i}=\frac{\int_{0}^{H} \mathrm{~d}_{z} \phi_{z i} \mathrm{~d}_{z}}{\int_{0}^{H} \phi_{z i}^{2} \mathrm{~d}_{z}} \times \frac{C_{\mathrm{L}}}{4 \pi \mathrm{S}_{n}^{2} K_{s i}}$,

where $\eta_{o i}$ is the peak tip deflection due to vortex shedding in the $i$ th mode of vibration in $\mathrm{m}, C_{\mathrm{L}}$ is the 0.16 , peak 
oscillatory lift coefficient, $K_{s i}$ is the mass damping parameter for the $i$ th mode of vibration, $S_{n}=0.2$, Strouhal number and $\phi_{z i}$ is the mode shape function normalized with respect to the dynamic amplitude at top of the chimney in the $i$ th mode of vibration.

Periodic response of the chimney in the $i$ th mode of vibration is very strongly dependent on a dimensionless mass damping parameter $K_{s i}$ calculated by the following formula:

$K_{s i}=\frac{2 m_{e i} \delta_{\mathrm{s}}}{\sigma d^{2}}$

where $m_{e i}$ is the equivalent mass per unit length in $\mathrm{kg} / \mathrm{m}$ in the $i$ th mode of vibration

$m_{e i}=\frac{\int_{0}^{H} m_{z} \phi_{z i}^{2} d_{z}}{\int_{0}^{H} \phi_{z i}^{2} d_{z}}$

where $\delta_{\mathrm{s}}$ is the logarithmic decrement of structural damping, $\sigma=1.2 \mathrm{~kg} / \mathrm{m}^{3}$, mass density of air and $d$ is the effective diameter taken as average diameter over the top $1 / 3$ rd height of the chimney in $m$.

The sectional shear force $\left(F_{z o i}\right)$ and bending moment $\left(M_{z o i}\right)$ at any height $z o$, for the $i$ th mode of vibration, shall be calculated from the following equation:

$F_{z o i}=4 \pi^{2} f_{i}^{2} \eta_{o i} \int_{z o}^{H} m_{z} \phi_{z i} \mathrm{~d} z$

$M_{z o i}=4 \pi^{2} f_{i}^{2} \eta_{o i} \int_{z o}^{H} m_{z} \phi_{z i}(z-z o) \mathrm{d} z$,

where $f_{i}$ is the natural frequency of chimney in the $i$ th mode of vibration in $\mathrm{Hz}$ and $m_{z}$ is the mass per unit length of the chimney at section $z$ in $\mathrm{kg} / \mathrm{m}$.
The fundamental mode of vibration is considered for computing the across-wind load. The fundamental natural frequencies of chimneys with fixed base are given in Table 3. In chimneys with fixed base, it is seen that as the height of chimney subsequently increases from 100 to $200 \mathrm{~m}$, from 200 to $300 \mathrm{~m}$ and from 300 to $400 \mathrm{~m}$, the natural frequency of chimney is reduced by 40-50, 25-35 and $22-26 \%$, respectively.

\section{Random response method}

Calculation of across-wind load is made by first calculating the peak response amplitude at the specified mode of vibration (usually the first or second). The taper of chimneys with slenderness ratio $\left(H / D_{\mathrm{b}}\right)$ that equals 7 was more than 1 in 50 and that of other chimneys was less than 1 in 50. Taper is defined as $\left\{2\left(d_{\mathrm{av}}-d_{\mathrm{top}}\right) / H\right\}$ where $d_{\mathrm{av}}$ is the average outer diameter over the top half of chimney and $d_{\text {top }}$ is the outer diameter at the top of chimney.

For chimney with little or no taper (average taper over the top one-third height is less than or equal to 1 in 50), the modal response, at a critical wind speed is calculated by the following formula:

$\eta_{o i}=\frac{\frac{1.25 \bar{C}_{\mathrm{L}} d \phi_{z_{i i} H_{i}}}{\pi^{2} \mathrm{~S}_{n}^{2}} \times \frac{\sigma d^{2} \sqrt{\frac{\sqrt{\pi L}}{2(n+2)}}}{m_{e i}}}{\left(\frac{1}{H} \int_{0}^{H} \phi_{z i}^{2} \mathrm{~d} z\right)^{\frac{1}{2}}\left(\beta-\left(\frac{k_{\mathrm{a}} \sigma d^{2}}{m_{e i}}\right)\right)^{\frac{1}{2}}}$,

where $\cap$ is the equivalent aspect ratio $=H / d, H$ is the height of chimney in $\mathrm{m}, d$ is the average diameter over the top $1 / 3$ rd height of chimney in $\mathrm{m}, \bar{C}_{\mathrm{L}}=0.12$, RMS lift coefficient, $L=1$, correlation length in diameters $k_{\mathrm{a}}=0.5$, aerodynamic damping co-efficient.

Table 3 Natural frequency of chimney with fixed base and flexible base

\begin{tabular}{|c|c|c|c|c|c|c|c|c|c|c|c|c|c|c|}
\hline \multirow[t]{3}{*}{$H(\mathrm{~m})$} & \multirow[t]{3}{*}{$H / D_{\mathrm{b}}$} & \multirow{3}{*}{$\begin{array}{l}\text { Natural frequency } \\
\text { of chimney with } \\
\text { fixed base }(\mathrm{Hz})\end{array}$} & \multicolumn{12}{|c|}{ Natural frequency of chimney due to the effect of SSI $(\mathrm{Hz})$} \\
\hline & & & \multicolumn{4}{|c|}{$D_{\mathrm{o}} / t=12.5$} & \multicolumn{4}{|c|}{$D_{\mathrm{o}} / t=17.5$} & \multicolumn{4}{|c|}{$D_{\mathrm{o}} / t=22.5$} \\
\hline & & & $\mathrm{S} 1$ & $\mathrm{~S} 2$ & S3 & S4 & $\mathrm{S} 1$ & $\mathrm{~S} 2$ & S3 & S4 & S1 & $\mathrm{S} 2$ & $\mathrm{~S} 3$ & S4 \\
\hline \multirow[t]{3}{*}{100} & 7 & 1.339 & 1.018 & 1.169 & 1.259 & 1.313 & 0.950 & 1.127 & 1.241 & 1.306 & 0.907 & 1.102 & 1.229 & 1.301 \\
\hline & 12 & 0.688 & 0.584 & 0.628 & 0.655 & 0.673 & 0.557 & 0.612 & 0.649 & 0.671 & 0.530 & 0.598 & 0.645 & 0.669 \\
\hline & 17 & 0.427 & 0.389 & 0.407 & 0.418 & 0.425 & 0.375 & 0.400 & 0.415 & 0.424 & 0.365 & 0.395 & 0.414 & 0.423 \\
\hline \multirow[t]{3}{*}{200} & 7 & 0.670 & 0.547 & 0.604 & 0.639 & 0.659 & 0.511 & 0.584 & 0.631 & 0.656 & 0.487 & 0.573 & 0.626 & 0.654 \\
\hline & 12 & 0.400 & 0.346 & 0.374 & 0.390 & 0.399 & 0.330 & 0.366 & 0.387 & 0.398 & 0.319 & 0.361 & 0.385 & 0.397 \\
\hline & 17 & 0.258 & 0.226 & 0.240 & 0.247 & 0.251 & 0.219 & 0.235 & 0.245 & 0.250 & 0.213 & 0.233 & 0.244 & 0.250 \\
\hline \multirow[t]{3}{*}{300} & 7 & 0.454 & 0.392 & 0.420 & 0.439 & 0.451 & 0.366 & 0.406 & 0.433 & 0.449 & 0.347 & 0.398 & 0.430 & 0.447 \\
\hline & 12 & 0.261 & 0.240 & 0.250 & 0.257 & 0.261 & 0.228 & 0.245 & 0.255 & 0.261 & 0.220 & 0.241 & 0.254 & 0.260 \\
\hline & 17 & 0.193 & 0.181 & 0.188 & 0.192 & 0.194 & 0.174 & 0.185 & 0.190 & 0.194 & 0.170 & 0.183 & 0.190 & 0.193 \\
\hline \multirow[t]{3}{*}{400} & 7 & 0.336 & 0.303 & 0.318 & 0.322 & 0.335 & 0.285 & 0.309 & 0.325 & 0.334 & 0.272 & 0.303 & 0.322 & 0.333 \\
\hline & 12 & 0.201 & 0.187 & 0.194 & 0.198 & 0.201 & 0.179 & 0.190 & 0.197 & 0.201 & 0.172 & 0.187 & 0.195 & 0.200 \\
\hline & 17 & 0.142 & 0.135 & 0.139 & 0.141 & 0.143 & 0.130 & 0.136 & 0.141 & 0.143 & 0.126 & 0.135 & 0.140 & 0.143 \\
\hline
\end{tabular}


Table 4 Base moment of chimney due to along and across wind load as per IS: 4998 (Part 1)-1992

\begin{tabular}{|c|c|c|c|c|c|}
\hline \multirow{3}{*}{$\begin{array}{l}\text { Height of chimney, } \\
H(\mathrm{~m})\end{array}$} & \multirow{3}{*}{$\begin{array}{l}\text { Slenderness } \\
\text { ratio }\left(H / D_{\mathrm{b}}\right)\end{array}$} & \multicolumn{4}{|c|}{ Base moments (kNm) } \\
\hline & & \multicolumn{2}{|c|}{ Along wind } & \multicolumn{2}{|l|}{ Across wind } \\
\hline & & $\begin{array}{l}\text { Simplified } \\
\text { method }\end{array}$ & $\begin{array}{l}\text { Random response } \\
\text { method }\end{array}$ & $\begin{array}{l}\text { Simplified } \\
\text { method }\end{array}$ & $\begin{array}{l}\text { Random response } \\
\text { method }\end{array}$ \\
\hline \multirow[t]{3}{*}{100} & 7 & 59,449 & 124,795 & 731,018 & 503,019 \\
\hline & 12 & 34,849 & 79,420 & 38,787 & 20,556 \\
\hline & 17 & 24,600 & 62,045 & 5316 & 2335 \\
\hline \multirow[t]{3}{*}{200} & 7 & 540,322 & 996,474 & $5,498,938$ & $4,535,521$ \\
\hline & 12 & 316,740 & 629,786 & 393,407 & 259,215 \\
\hline & 17 & 223,581 & 485,981 & 57,683 & 30,173 \\
\hline \multirow[t]{3}{*}{300} & 7 & $1,957,856$ & $3,335,420$ & $17,553,686$ & $14,316,742$ \\
\hline & 12 & $1,138,288$ & $2,124,915$ & $1,132,171$ & 739,151 \\
\hline & 17 & 819,568 & $1,638,583$ & 230,940 & 132,810 \\
\hline \multirow[t]{3}{*}{400} & 7 & $4,930,240$ & $7,481,986$ & $39,879,581$ & $32,339,199$ \\
\hline & 12 & $2,872,401$ & $5,087,830$ & $7,841,886$ & $5,082,837$ \\
\hline & 17 & $2,057,839$ & $3,958,270$ & 515,128 & 285,123 \\
\hline
\end{tabular}

For the chimney which is significantly tapered (average taper over the top one-third height is more than 1 in 50), the modal response is calculated by the following formula:

$\eta_{o i}=\frac{\sigma \bar{C}_{\mathrm{L}} d_{z e}^{4} \phi_{z e i} \phi_{z i} H_{i}\left(\frac{\pi L}{2 t}\right)^{\frac{1}{2}}}{2 \pi^{2} \mathrm{~S}_{n}^{2} m_{e i} \int_{0}^{H} \phi_{z i}^{2} \mathrm{~d} z\left(\beta-\frac{k_{\mathrm{a}} \sigma d^{2}}{m_{e i}}\right)^{\frac{1}{2}}}$,

where, zei is the height in meter at which $d_{z}^{4} \phi_{z i} / \sqrt{t}$ is maximum in the $i$ th mode of vibration in $\mathrm{m}$

$t=\left\{\frac{-\delta}{\delta_{z}} d_{z}+\frac{\alpha d_{z}}{z}\right\}_{z=z e i}$

where, $\alpha$ is the power law exponent. For terrain category 2, the value of $\alpha$ is 0.14 .

The across-wind and along-wind loads for tall RC chimneys were obtained by both simplified and random response methods. The base moments of chimney due to across-wind and along-wind loads are shown in Table 4. It is found that the base moment of the chimney computed from simplified method is lower than that from the random response method when it is subjected to along-wind load. The variation of base moment obtained from random response method and simplified method decreases with increase in chimney elevation. In the lower elevation chimney $(H=100 \mathrm{~m})$ with different $H / D_{\mathrm{b}}$ ratios, the variation of base moment of $110-152 \%$ is found between the two methodologies, whereas in higher elevation chimneys $(H=400 \mathrm{~m})$ this variation between the two methods is 52-92\%. In the case of across-wind load, the higher base moment of chimney is obtained from simplified method. The variation of base moment of all chimneys estimated from the two methods ranges in 18-56\%. The above variation is caused by the difference in the value of $\eta_{o i}$.
The wind load for which the maximum base moment of the chimney is obtained is selected out of the across-wind and along-wind loads for SSI analysis. This wind load is applied to the finite element model of chimney at various locations along the height of chimney. It is also found that for stocky chimneys $\left(H / D_{\mathrm{b}}=7\right)$, the maximum base moment is obtained due to across-wind load and for slender chimneys $\left(H / D_{\mathrm{b}}=17\right)$, the base moment of chimney is maximum due to along-wind load. It is also observed that the maximum base moment of 100, 200 and $300 \mathrm{~m}$ chimneys with $H / D_{\mathrm{b}}=12$ is obtained when it is subjected to along-wind load, whereas across-wind load causes maximum base moment in $400 \mathrm{~m}$ tall chimney.

\section{Finite element model of chimney-piled raft-soil system}

The three-dimensional finite element analysis of chimney with fixed base and integrated chimney-piled raft-soil system was carried out using the finite element software ANSYS. The chimney and the raft were modelled using four-noded SHELL63 element, which has both bending and membrane capabilities. This element has six degrees of freedom at each node. Eight-noded SOILD45 elements with three translational degrees of freedom at each node were used for the three-dimensional modelling of the soil and the pile. The surface-surface contact elements were used to model the interaction between pile and soil. The pile surface was established as "target" surface (TARGE170), and the soil surface contacting the pile as "contact" surface (CONTAC174); these two surfaces 
constitute the contact pair. The coefficient of friction was defined between contact and target surfaces and is given in Table 2. The lateral movements at the soil boundaries were restrained. All movements were restrained at bed rock level. The nodes at the interface of bottom of raft and top of soil were completely coupled.

The chimney shell was discretised with element of $2 \mathrm{~m}$ size along height and with divisions of $7.5^{\circ}$ in the circumferential direction. The diameter and thickness of chimney were varied linearly along the entire height. The pile was discretised with 14 elements of same size along the length of pile.

Elastic continuum approach was adopted for modelling the soil. The material properties such as elastic modulus, Poisson's ratio and density for the three-dimensional soil stratum are given in Table 2. The integrated chimneyfoundation-soil system was analysed based on direct method of SSI by assuming the linear elastic behaviour of the whole system.

The wind load computed as per IS: 4998(Part 1)-1992 (2003) was applied in the chimney as point loads at $10 \mathrm{~m}$ intervals along its height after suitably averaging the load above and below each section. The gravity load was also applied to the SSI model. Finite element model of $100 \mathrm{~m}$ chimney $\left(H / D_{\mathrm{b}}=7\right)$ with fixed base subjected to acrosswind load is shown in Fig. 2. Three-dimensional finite element model of the integrated chimney-piled raft-soil system was generated using the ANSYS software and is shown in Fig. 3. The finite element model of piled raft foundation and that of a single pile are shown in Fig. 4.

The responses of chimney in terms of lateral deflection, base moment, tangential moments and radial moments were investigated. The responses of chimney obtained from the SSI analysis of chimney-piled raft system were compared with that obtained from chimney with fixed base. The results obtained from finite element analysis of chimney with fixed base are designated as "Fixed" in graphs and tables. The percentage variation of maximum values of the moments in the chimney considering SSI from those obtained from the finite element analysis of chimney with fixed base was computed. The effect of SSI was studied by considering different parameters such as flexibility of soil, stiffness of the raft of piled raft foundation, slenderness ratio of the chimney and chimney elevation.

\section{Results and discussions}

Finite element analysis was conducted on 144 integrated three-dimensional chimney-piled raft-soil systems under wind loads applied along the height of chimney to study the effect of SSI in wide range of chimneys with piled raft
Fig. 2 Finite element model of $100 \mathrm{~m}$ chimney $\left(H / D_{\mathrm{b}}=7\right)$ with fixed base

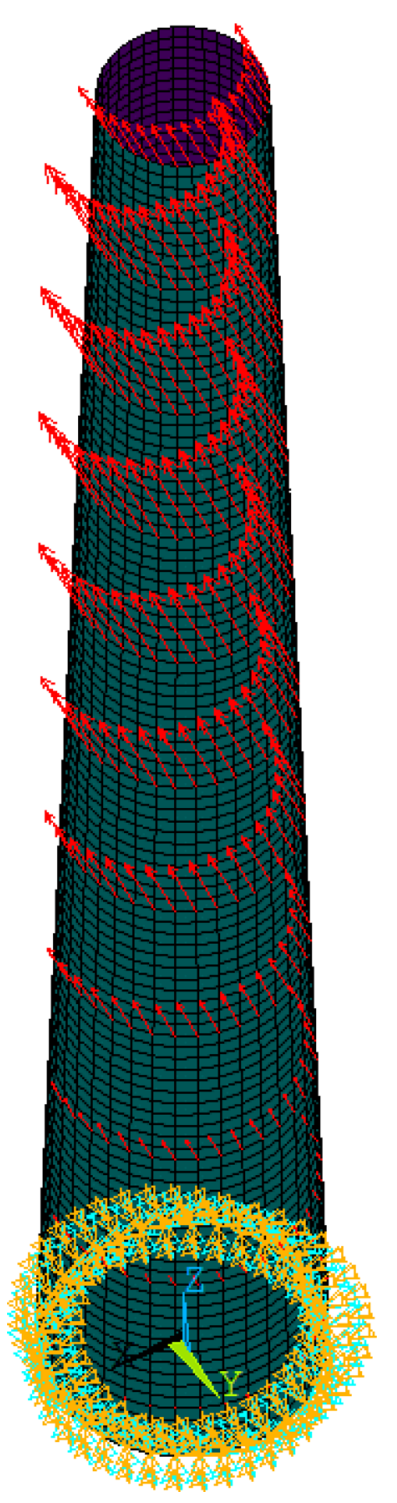

foundations subjected to wind loads. The responses of chimney such as lateral deflection, base moment, tangential and radial moments, etc. were analysed. The variation of response of chimney with flexible base from that of chimney with fixed base was computed. The maximum response is obtained at the leeward side of the chimney and, therefore, the different responses at the leeward side of chimney are shown in the following graphs. The effect of flexibility of soil, stiffness of raft of piled raft foundation, slenderness ratio of chimney and of chimney elevation on the above variation is studied.

\section{Effect of flexibility of soil}

To study the effect of SSI, four types of soils were selected namely S1, S2, S3 and S4 representing loose sand, medium sand, dense sand and rock respectively. The natural 


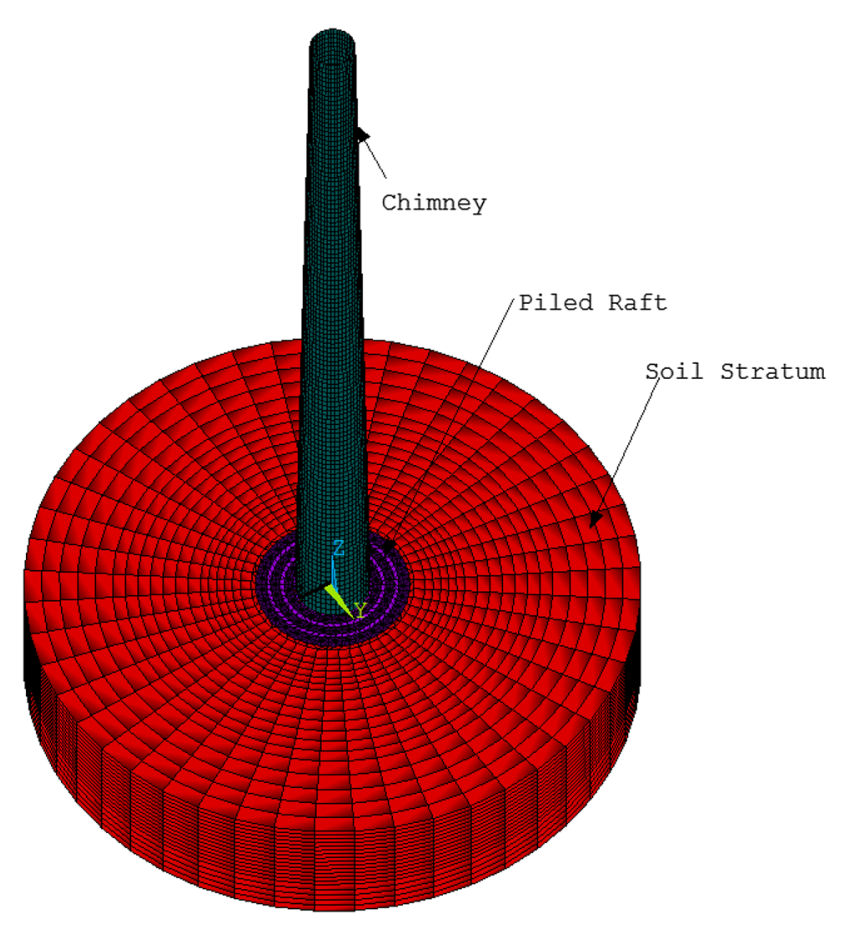

Fig. 3 Finite element model of integrated $200 \mathrm{~m}$ chimney (H/ $D_{\mathrm{b}}=12$ )-piled raft-soil system
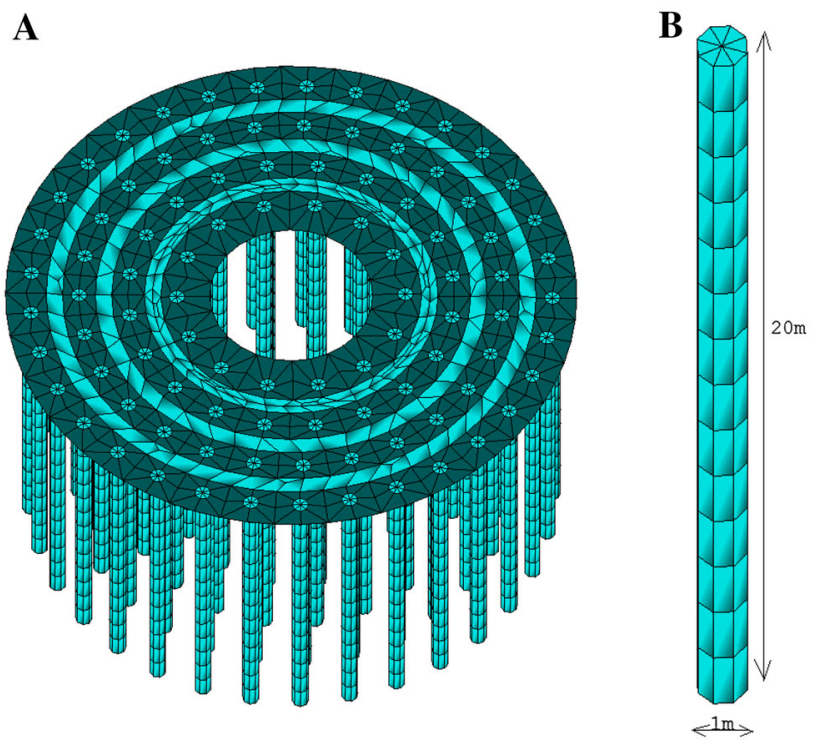

Fig. 4 Finite element model of a piled raft and $\mathbf{b}$ pile

frequency, lateral deflection and moments of the chimney were evaluated considering fixed base and flexible base for the chimney.

\section{Variation of natural frequency of chimney}

The natural frequencies obtained from SSI analysis were compared with that obtained from the analysis of chimney with fixed base and is given in Table 3 . The fundamental natural frequency obtained from chimney with fixed base is higher than that obtained from SSI analysis. The variation of fundamental frequency of chimney with flexible base from that of chimney with rigid base is more for $100 \mathrm{~m}$ chimney $\left(H / D_{\mathrm{b}}=7\right.$ and $\left.D_{\mathrm{o}} / t=22.5\right)$ resting on soil type $\mathrm{S} 1$ and the variation is $32.26 \%$. The variations of same chimney resting on soil types S2, S3 and S4 are 17.69, 8.21 and $2.83 \%$, respectively. It is seen that the percentage variation of natural frequency between that of flexible base and fixed base conditions of chimney is considerable for soil type S1 and S2. Due to interaction with stiff soil types $\mathrm{S} 3$ and S4, the above variation is less than $10 \%$. Therefore, it can be inferred that the SSI effect is prominent on flexible soil types rather than stiff soil types.

\section{Variation of lateral deflection of chimney}

The lateral deflection of chimney is obtained from the analysis of chimney with piled raft foundation considering the SSI effect and fixity at the base of chimney. The contour of lateral displacement of $200 \mathrm{~m}$ chimney $\left(H / D_{\mathrm{b}}=7\right.$ and $D_{\mathrm{o}} / t=22.5$ ) resting on the four soil types and that of same chimney with fixed base are shown in Fig. 5. The lateral deflection along the height of 100, 200, 300 and $400 \mathrm{~m}$ chimney $\left(H / D_{\mathrm{b}}=12\right)$ with piled raft $\left(D_{\mathrm{o}} / t=22.5\right)$ foundation obtained from fixed base analysis and SSI analysis is shown in Fig. 6. It is found that the deflection of chimney increases with increase in flexibility of soil. The deflection is maximum at the tip of chimney for all cases. The tip deflection is tabulated in Table 5. It is seen that in general, the tip deflection of chimney obtained from the analysis of chimney with fixed base is lower than that obtained from the SSI analysis. Maximum increase in tip deflection of $89 \%$ is found for $100 \mathrm{~m}$ chimney $\left(H / D_{\mathrm{b}}=7\right)$ with piled raft $\left(D_{\mathrm{o}} / t=22.5\right)$ under flexible soil type $\mathrm{S} 1$ from the chimney with fixed base. For the same chimneyfoundation system, the maximum variation of tip deflection of chimney resting on soil type S2, S3 and S4 from that of chimney with fixed base is 39,17 and $6 \%$, respectively. The soil-structure interaction studies are relevant for chimneys resting on soil types $\mathrm{S} 1$ and $\mathrm{S} 2$ as the variation of tip deflection from fixed base analysis is significant for all chimneys considered.

\section{Variation of tangential moment in chimney}

The tangential bending moments in chimney is evaluated from the SSI analysis and fixed base analysis of chimney. The contours of tangential moment of 200 m chimney (H/ $D_{\mathrm{b}}=7$ and $\left.D_{\mathrm{o}} / t=22.5\right)$ supported on different soil types and with fixed base are shown in Fig. 7. The tangential moment at various locations along the height of $100 \mathrm{~m}$ chimney in the leeward side is shown in Fig. 8 for the SSI 
Fig. 5 Contour of lateral deflection $(\mathrm{m})$ of $200 \mathrm{~m}$ chimney $\left(H / D_{\mathrm{b}}=7\right.$ and $\left.D_{\mathrm{o}} / t=22.5\right)$ resting on soil types a S1, b S2, c S3, d S4 and e fixed base
A

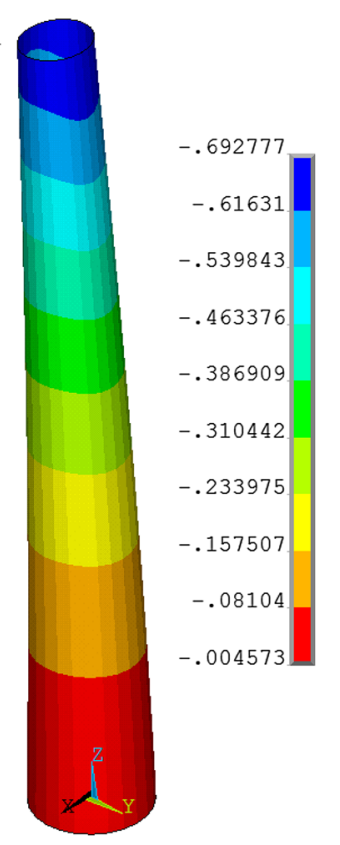

D

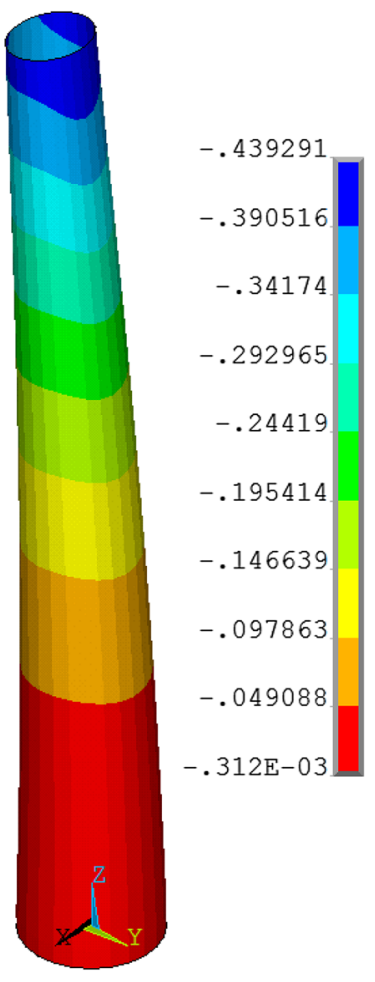

B

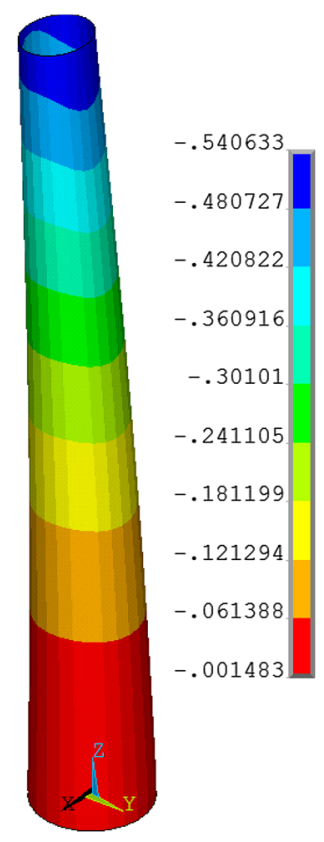

C

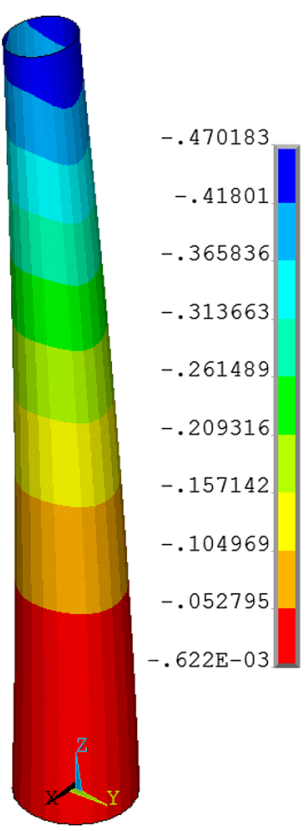

E

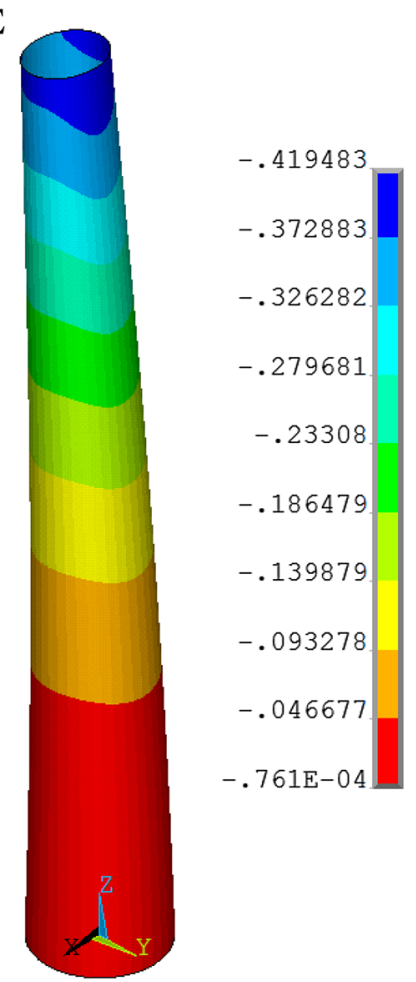

and fixed base cases. It is observed that the maximum tangential moment in chimney with fixed base is obtained at a height of $\mathrm{H} / 3$ from the top. The wind load intensity is more in this region of chimney. It is seen that tangential moments are high at the bottom of the chimney also but not the maximum for the case of chimney with fixed base. The maximum tangential moment is obtained at $H / 3 \mathrm{~m}$ from the top of chimney in the case of chimney founded on supporting soil type $\mathrm{S} 4$ also which is the same as in the above said case of chimney with fixed base. It is observed that the maximum tangential moment of chimney is obtained at the base of chimney when it rests on soil type S1 and S2. It is 

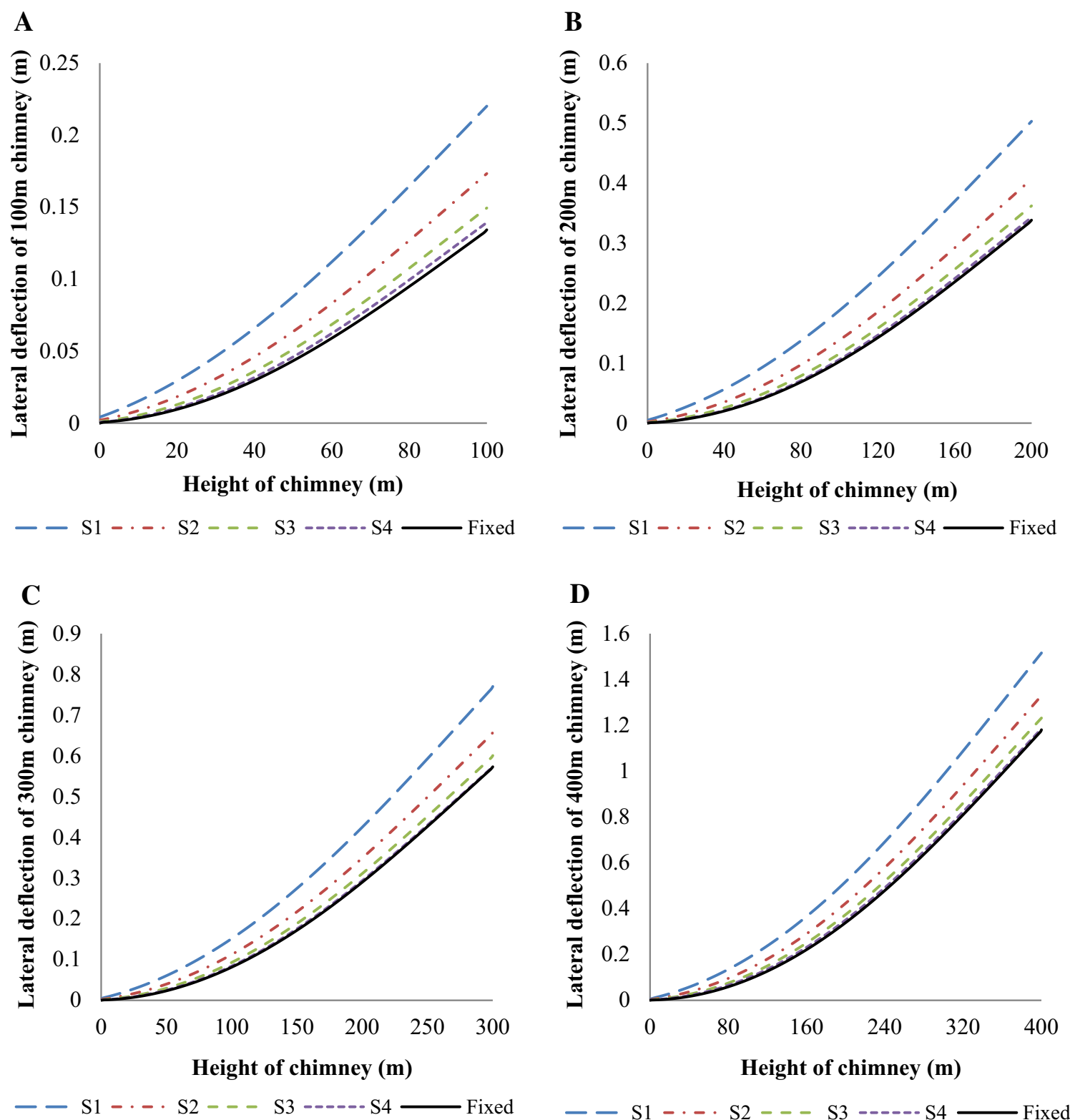

Fig. 6 Lateral deflection of a $100 \mathrm{~m}, \mathbf{b} 200 \mathrm{~m}, \mathbf{c} 300 \mathrm{~m}, \mathbf{d} 400 \mathrm{~m}$ chimney $\left(H / D_{\mathrm{b}}=12\right.$ and $\left.D_{\mathrm{o}} / t=22.5\right)$ with flexible and fixed base

found that the higher moments occur at the base as well as at $H / 3 \mathrm{~m}$ from the top of chimney when it is supported on soil type S3. The above observations correspond to stocky chimneys $\left(H / D_{\mathrm{b}}=7\right)$. All other chimneys show the maximum tangential moment at the base of chimney itself due to the SSI effect.

From the SSI analysis, it is found that the tangential bending moment in chimney increases with increase in flexibility of soil. It is also noticed that the effect of soil flexibility on tangential moment is negligible beyond $H /$ $20 \mathrm{~m}$ height from the base of chimney. The variation of tangential moment of chimney with flexible base from that with fixed base is seen only up to the height of $H / 20$ from the base of the chimney. These variations for a height of $H$ / $10 \mathrm{~m}$ from the base of 100, 200, 300 and $400 \mathrm{~m}$ chimneys $\left(H / D_{\mathrm{b}}=7\right.$ and $\left.D_{\mathrm{o}} / t=22.5\right)$ are shown in Fig. 9. The percentage variation of maximum tangential moment of chimney with flexible base from that with fixed base is tabulated in Table 6 . The maximum variation of $713 \%$ of tangential moments is observed for very slender $400 \mathrm{~m}$ chimney with flexible raft $\left(H / D_{\mathrm{b}}=17\right.$ and $\left.D_{\mathrm{o}} / t=22.5\right)$ founded on loose sand and the corresponding variations when it interacts with S2, S3 and S4 soil types are 400, 214 and $116 \%$, respectively. 
Table 5 Lateral deflection of chimney with fixed base and flexible base

\begin{tabular}{|c|c|c|c|c|c|c|c|c|c|c|c|c|c|c|}
\hline \multirow[t]{3}{*}{$H(\mathrm{~m})$} & \multirow[t]{3}{*}{$H / D_{\mathrm{b}}$} & \multirow{3}{*}{$\begin{array}{l}\text { Tip deflection of } \\
\text { chimney with } \\
\text { fixed base }(m)\end{array}$} & \multicolumn{12}{|c|}{ Tip deflection of chimney due to chimney-piled raft-soil interaction (m) } \\
\hline & & & \multicolumn{4}{|c|}{$D_{\mathrm{o}} / t=12.5$} & \multicolumn{4}{|c|}{$D_{\mathrm{o}} / t=17.5$} & \multicolumn{4}{|c|}{$D_{\mathrm{o}} / t=22.5$} \\
\hline & & & $\mathrm{S} 1$ & $\mathrm{~S} 2$ & S3 & S4 & $\mathrm{S} 1$ & $\mathrm{~S} 2$ & S3 & S4 & $\mathrm{S} 1$ & $\mathrm{~S} 2$ & S3 & S4 \\
\hline \multirow[t]{3}{*}{100} & 7 & 0.18 & 0.28 & 0.23 & 0.20 & 0.19 & 0.31 & 0.24 & 0.21 & 0.19 & 0.34 & 0.25 & 0.21 & 0.19 \\
\hline & 12 & 0.13 & 0.18 & 0.16 & 0.15 & 0.14 & 0.20 & 0.17 & 0.15 & 0.14 & 0.22 & 0.17 & 0.15 & 0.14 \\
\hline & 17 & 0.41 & 0.52 & 0.47 & 0.44 & 0.43 & 0.56 & 0.49 & 0.47 & 0.43 & 0.60 & 0.50 & 0.45 & 0.43 \\
\hline \multirow[t]{3}{*}{200} & 7 & 0.42 & 0.58 & 0.50 & 0.46 & 0.44 & 0.64 & 0.53 & 0.47 & 0.44 & 0.70 & 0.55 & 0.48 & 0.44 \\
\hline & 12 & 0.34 & 0.44 & 0.39 & 0.36 & 0.35 & 0.48 & 0.40 & 0.36 & 0.35 & 0.51 & 0.41 & 0.37 & 0.35 \\
\hline & 17 & 1.00 & 1.08 & 0.97 & 0.92 & 0.89 & 1.16 & 1.01 & 0.93 & 0.89 & 1.22 & 1.03 & 0.94 & 0.90 \\
\hline \multirow[t]{3}{*}{300} & 7 & 0.59 & 0.74 & 0.67 & 0.63 & 0.61 & 0.84 & 0.71 & 0.64 & 0.61 & 0.90 & 0.73 & 0.65 & 0.61 \\
\hline & 12 & 0.57 & 0.66 & 0.61 & 0.59 & 0.57 & 0.72 & 0.64 & 0.60 & 0.57 & 0.77 & 0.66 & 0.60 & 0.57 \\
\hline & 17 & 1.66 & 1.89 & 1.77 & 1.71 & 1.67 & 2.01 & 1.83 & 1.73 & 1.68 & 2.11 & 1.87 & 1.74 & 1.68 \\
\hline \multirow[t]{3}{*}{400} & 7 & 0.75 & 0.79 & 0.73 & 0.69 & 0.66 & 0.87 & 0.76 & 0.70 & 0.67 & 0.95 & 0.79 & 0.71 & 0.67 \\
\hline & 12 & 1.18 & 1.34 & 1.27 & 1.23 & 1.20 & 1.44 & 1.32 & 1.24 & 1.20 & 1.54 & 1.35 & 1.25 & 1.21 \\
\hline & 17 & 2.09 & 2.36 & 2.25 & 2.18 & 2.14 & 2.52 & 2.32 & 2.20 & 2.14 & 2.66 & 2.37 & 2.22 & 2.15 \\
\hline
\end{tabular}

\section{Variation of radial moment in chimney}

The contour of the radial moment in chimney $(H=200 \mathrm{~m}$, $H / D_{\mathrm{b}}=7$ and $\left.D_{\mathrm{o}} / t=22.5\right)$ resting on four different soil types and that with fixed base are shown in Fig. 10. It is seen that the maximum radial moment is obtained at the base of the chimney for all the analysis cases considered with and without SSI effect. The radial moments up to a height of $H / 10$ from the base of chimneys $\left(H / D_{\mathrm{b}}=7\right.$ and $\left.D_{\mathrm{o}} / t=22.5\right)$ are shown in Fig. 11. The radial bending moment in chimney increases with increase in flexibility of soil. It is also observed that the variation of radial moments of chimney due to different supporting soil conditions is seen only up to a height of $H / 40$ from the base of the chimney. The effect of soil flexibility on radial moments is negligible beyond this $H / 40$ height from the base of chimney. It is inferred that the state of stress developed at the base of chimney modelled with piled raft foundation and surrounding soil is different from that in the case of fixity at base due to the interaction among these three components. This effect naturally decays after a particular height above the base as the height of chimney is very large in comparison with the diameter at base. Hence the response variation at base for a distance of at least 1/40th of the height of chimney should be considered for safe design.

The maximum radial bending moments in chimney with and without SSI effect are tabulated in Table 7. Unlike tangential moments in chimney, the maximum radial moment of lower elevation chimneys $\left(H=100 \mathrm{~m}\right.$ and $\left.H / D_{\mathrm{b}}=12\right)$ with piled raft foundation having thin raft resting on soil type $S 1$ is increased by 11-14 times of that of chimney with fixed base. This is the highest variation of radial moment of chimney with flexible base from that of chimney with fixed base obtained from all the analysis under consideration. Similarly, for this chimney supported on soil types $S 2, S 3$ and $S 4$, the maximum variation is eight, four and two times of that of chimney with fixed base. The effect of SSI on the radial moment in chimney is more for lower elevation chimneys with a flexible raft while interacting with loose sand.

\section{Variation in the base moment of chimney}

The base moment of chimney was computed for alongwind load and across-wind load according to IS: 4998(Part 1)-1992 (2003) based on two methods. The wind load which caused the maximum base moment was applied to the SSI system and for this lateral load the base moment of chimney with flexible base was evaluated. The base moment obtained from the chimney with flexible base is compared with that obtained from the chimney with fixed base. The variations of base moment evaluated from both cases are shown in Table 8 . It is found that the base moment of chimney increases with increase in stiffness of supporting soil. It is also seen that the base moment is maximum in chimneys with fixed base as compared to flexible base. The base moment of the $100 \mathrm{~m}$ chimney evaluated from the SSI analysis of chimney $\left(H / D_{\mathrm{b}}=17\right.$, $D_{\mathrm{o}} / t=22.5$ and soil type S4) is decreased by $64 \%$ from that estimated from the chimney with fixed base. This is the minimum variation found between chimneys of flexible and fixed base. The maximum variation among both the cases is seen for a 400-m chimney $\left(H / D_{\mathrm{b}}=7, D_{\mathrm{o}} / t=22.5\right.$ and soil type $\mathrm{S} 4$ ) and the reduction is $97 \%$. It is seen that the base moment of chimney obtained from the chimneypiled raft system resting on rock is much less than that obtained from the chimney with fixed base. 
Fig. 7 Contour of tangential moment $(\mathrm{kNm})$ of $200 \mathrm{~m}$ chimney $\left(H / D_{\mathrm{b}}=7\right.$ and $\left.D_{\mathrm{o}} / t=22.5\right)$ resting on soil types a S1, b S2, c S3, d S4 and e fixed base
A

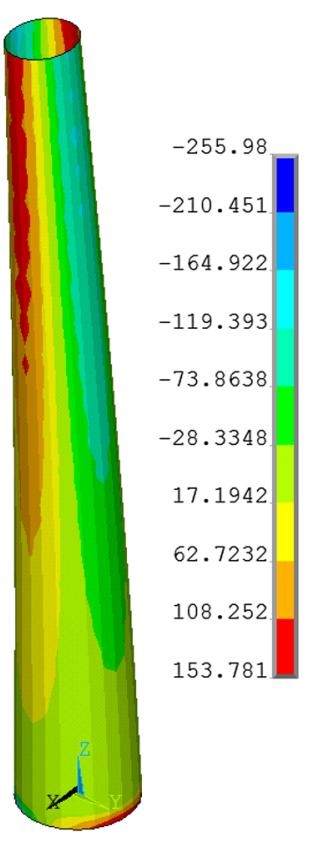

D

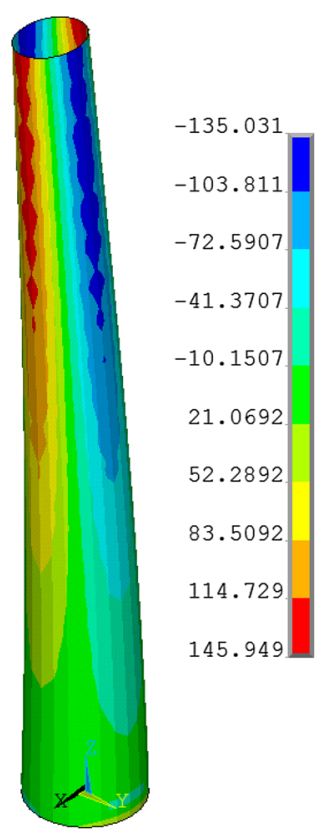

B

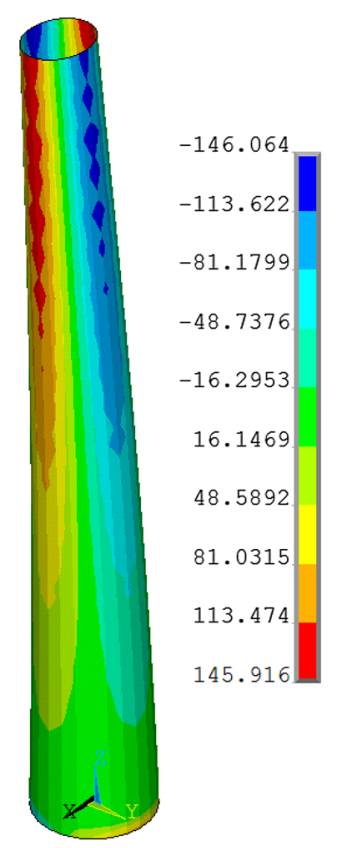

C

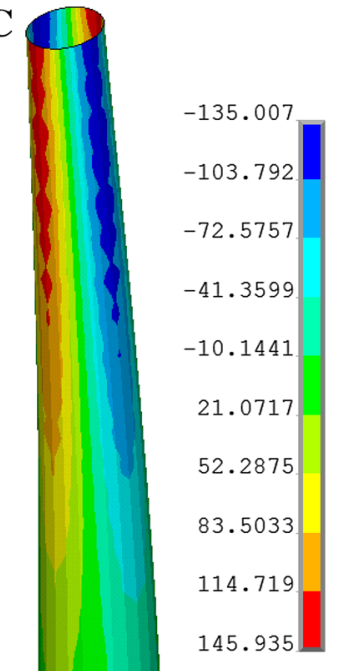

E

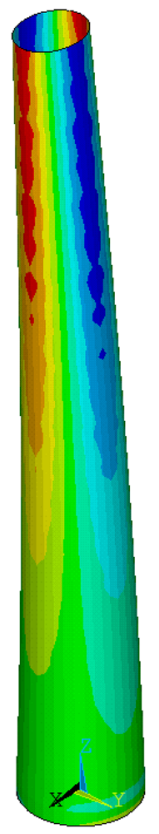

-143.163
-109.74
-76.3174
-42.8947
-9.47203
23.9507
57.3733
90.796
124.219
157.641

\section{Effect of stiffness of raft}

The effect of stiffness of raft of piled raft foundation was investigated by considering three different $D_{\mathrm{o}} / t$ ratios $\left(D_{\mathrm{o}} / t=12.5,17.5\right.$, and 22.5) for the raft. It is seen that the response in chimney such as lateral deflection, tangential and radial moments and base moments increase with increase in $D_{\mathrm{o}} / t$ ratio. The stiffness of the foundation is less for higher $D_{\mathrm{o}} / t$ ratios of the raft and, therefore, the bending of chimney will be more at the base when it is subjected to the lateral wind load.

The maximum variation in lateral deflection of chimney with flexible base from that of fixed base is observed for the 100-m chimney $\left(H / D_{\mathrm{b}}=7\right)$ resting on loose sand and the variations for $D_{\mathrm{o}} / t$ ratios of $12.5,17.5$ and 22.5 are 56 , 72 and $89 \%$, respectively. The representative figures of tangential and radial bending moments in the $100-\mathrm{m}$ chimney for different Do/t ratios are shown in Fig. 12. It is 
Fig. 8 Tangential moment of $100 \mathrm{~m}$ chimney $\left(D_{\mathrm{o}} / t=12.5\right)$ with different $H / D_{\mathrm{b}}$ ratios of a 7 , b 12 and c 17

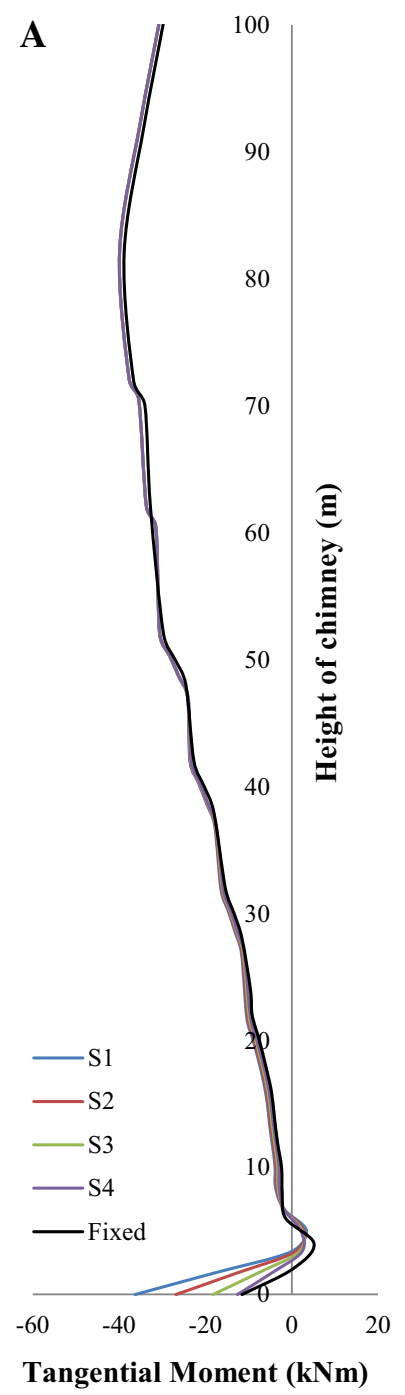

Tangential Moment (kNm)
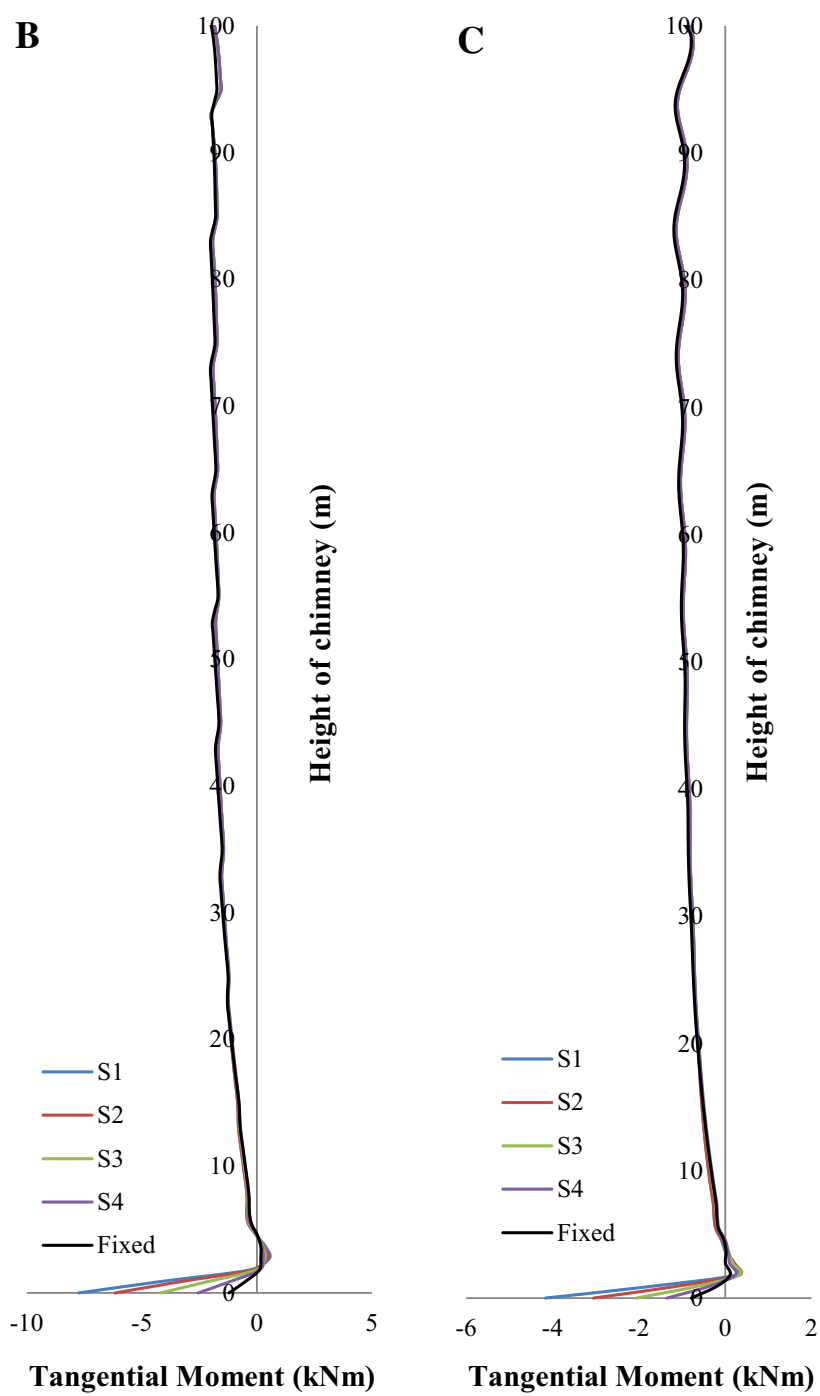

also found that the variation of moments in chimney with respect to different $D_{\mathrm{o}} / t$ ratios is only seen for a few metre heights $(H / 10 \mathrm{~m})$ from the base of the chimney. There is no effect of stiffness of raft on the moment response in chimney beyond this height. The tangential moment of chimney is increased by four times of that of fixed base due to SSI for $D_{\mathrm{o}} / t=12.5$. For other $D_{\mathrm{o}} / t$ ratios of 17.5 and 22.5 , the tangential moment of chimney with flexible base is increased by 2-6 and 2-8 times, respectively, of that of chimney with fixed base. Significant variation in bending moments in the chimney is found due to the effect of stiffness of raft of piled raft foundation and the effect is less in very tall chimneys. The variation of base moment of $400 \mathrm{~m}$ chimney is less than that of $100 \mathrm{~m}$ chimneys due to variation in $D_{\mathrm{o}} / t$ ratios. All the above comparisons correspond to the chimney-foundation system supported on loose sand.

\section{Effect of slenderness ratio of chimney}

The effect of slenderness ratio of chimney was studied by considering three $H / D_{\mathrm{b}}$ ratios $\left(H / D_{\mathrm{b}}=7,12\right.$ and 17$)$ of chimney representing the range of stocky to slender chimneys. For stocky chimneys the across-wind loading produces maximum base moment but for other chimneys, along-wind load produces the maximum base moment. It is noted that the along-wind load in chimney with $H / D_{\mathrm{b}}=12$ is lesser than across-wind load in chimney with $H / D_{\mathrm{b}}=7$. The chimneys were analysed for these loads causing maximum base moment as considered in design office. The tip deflection of chimney is maximum for chimneys of $H$ / $D_{\mathrm{b}}=17$ compared to other two $H / D_{\mathrm{b}}$ ratios. The tip deflection is found less for chimneys of $H / D_{\mathrm{b}}=12$ for 100 , 200 and $300 \mathrm{~m}$ chimneys. This is due to the lesser intensity of along-wind loading. For the case of $400 \mathrm{~m}$ chimney, the 

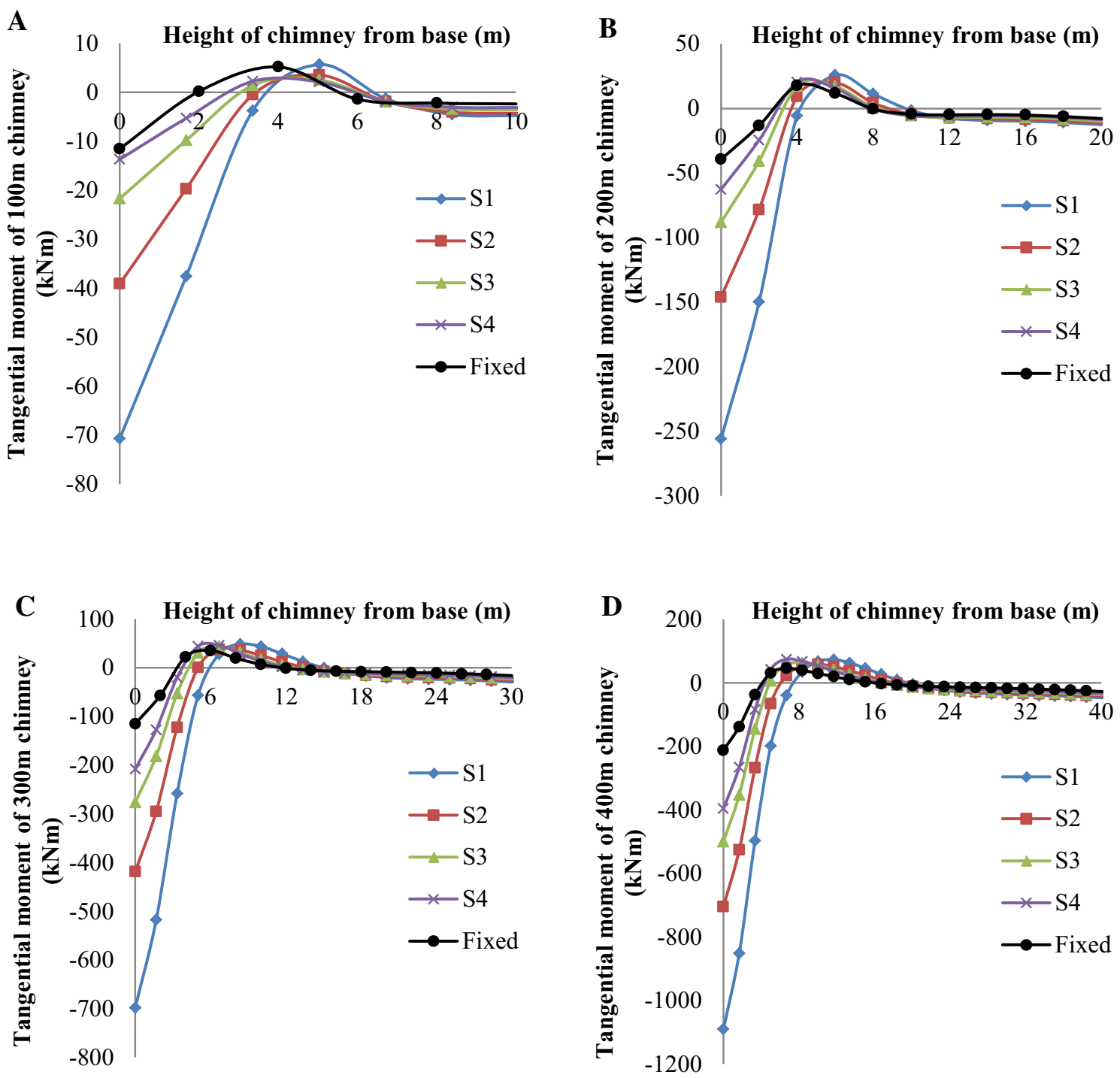

Fig. 9 Tangential moment of a $100 \mathrm{~m}$, b $200 \mathrm{~m}$, c $300 \mathrm{~m}, \mathbf{d} 400 \mathrm{~m}$ chimney $\left(H / D_{\mathrm{b}}=7\right.$ and $\left.D_{\mathrm{o}} / t=22.5\right)$ with flexible and fixed base

tip deflection increases with slenderness of chimney. Therefore, the chimney of $H / D_{\mathrm{b}}=7$ subjected to acrosswind load shows more tip deflection compared to that of $H /$ $D_{\mathrm{b}}=12$ subjected to along-wind load. It is seen that all response of chimneys with $H / D_{\mathrm{b}}=12$ subjected to alongwind loading is lesser than that in chimneys with $H / D_{\mathrm{b}}=7$ subjected to across-wind load due to the difference in intensity of loading.

The representative figures for tangential moments in the 100-m chimney for different $H / D_{\mathrm{b}}$ ratios of chimney-piled raft-soil system are shown in Fig. 8. From the SSI analysis, it is observed that stocky chimneys $\left(H / D_{\mathrm{b}}=7\right)$ with flexible base shows higher tangential moments at a depth of $H /$ 3 from the top of chimney, especially when the chimneypiled raft system rests on dense sand and rock. This is similar to the response of chimney with fixed base and is different from the response of chimneys with $H / D_{\mathrm{b}}=12$ and $H / D_{\mathrm{b}}=17$ with flexible base. The SSI analysis of chimney with $H / D_{\mathrm{b}}$ ratios of 12 and 17 shows that the tangential moment is high at the base. The maximum tangential moment in stocky chimney with flexible base is 2.5 times of that in chimney with fixed base. For $H / D_{\mathrm{b}}$ ratios of 12 and 17 , it is more than 2.5-8 times of that with fixed base. Similar variation is found in maximum radial moment also. It is found that the effect of SSI is more for slender chimneys $\left(H / D_{\mathrm{b}}=17\right)$. The variation of base moment of $100 \mathrm{~m}$ chimneys among different slenderness ratios is considerable than that in other chimneys. In general, the SSI effect is more in slender chimneys compared to stocky chimneys because of the less gravitational force 
Table 6 Variation of tangential moment of chimney due to chimney-piled raft-soil interaction

\begin{tabular}{|c|c|c|c|c|c|c|c|c|c|c|c|c|c|c|}
\hline \multirow[t]{3}{*}{$H(\mathrm{~m})$} & \multirow[t]{3}{*}{$H / D_{\mathrm{b}}$} & \multirow{3}{*}{$\begin{array}{l}\text { Tangential } \\
\text { moment of } \\
\text { chimney with } \\
\text { fixed base } \\
(\mathrm{kNm})\end{array}$} & \multicolumn{12}{|c|}{ Percentage variation of tangential moment of chimney due to chimney-piled raft-soil interaction (\%) } \\
\hline & & & \multicolumn{4}{|c|}{$D_{\mathrm{o}} / t=12.5$} & \multicolumn{4}{|c|}{$D_{\mathrm{o}} / t=17.5$} & \multicolumn{4}{|c|}{$D_{\mathrm{o}} / t=22.5$} \\
\hline & & & S1 & S2 & S3 & S4 & S1 & $\mathrm{S} 2$ & S3 & S4 & S1 & S2 & S3 & S4 \\
\hline \multirow[t]{3}{*}{100} & 7 & 38.845 & 2.66 & 2.67 & 2.69 & 2.71 & 45.57 & 2.65 & 2.68 & 2.70 & 82.05 & 2.63 & 2.68 & 2.70 \\
\hline & 12 & 2.4374 & 217.85 & 153.10 & 72.23 & 4.75 & 425.31 & 262.28 & 102.46 & 9.01 & 699.21 & 377.35 & 123.66 & 13.50 \\
\hline & 17 & 1.8456 & 125.55 & 65.24 & 11.14 & -3.23 & 268.41 & 116.68 & 16.91 & -3.23 & 378.22 & 132.10 & 7.92 & -3.23 \\
\hline \multirow[t]{3}{*}{200} & 7 & 139.16 & 0.88 & -2.98 & -2.97 & -2.96 & 49.03 & -3.00 & -2.98 & -2.97 & 83.92 & 4.94 & -2.98 & -2.97 \\
\hline & 12 & 9.0026 & 216.70 & 121.20 & 43.14 & 2.08 & 376.90 & 182.63 & 58.85 & 2.08 & 482.00 & 216.33 & 68.24 & 5.17 \\
\hline & 17 & 4.7856 & 157.46 & 103.02 & 46.78 & 30.51 & 332.86 & 184.39 & 73.89 & 30.51 & 471.95 & 238.66 & 91.99 & 30.51 \\
\hline \multirow[t]{3}{*}{300} & 7 & 276.91 & 51.34 & 14.66 & 7.72 & 7.73 & 107.66 & 36.46 & 7.71 & 7.73 & 151.89 & 51.11 & 7.70 & 7.72 \\
\hline & 12 & 17.511 & 284.49 & 179.68 & 100.71 & 51.97 & 452.18 & 248.81 & 122.72 & 58.54 & 578.03 & 292.92 & 135.48 & 62.78 \\
\hline & 17 & 9.5946 & 293.17 & 199.48 & 121.11 & 66.67 & 501.42 & 293.01 & 153.62 & 76.15 & 671.80 & 358.28 & 173.53 & 81.52 \\
\hline \multirow[t]{3}{*}{400} & 7 & 470.81 & 149.70 & 116.52 & 107.38 & 107.39 & 194.80 & 135.59 & 107.37 & 107.38 & 231.58 & 149.67 & 107.36 & 107.38 \\
\hline & 12 & 56.109 & 275.47 & 180.63 & 111.52 & 67.11 & 420.18 & 244.15 & 134.08 & 74.01 & 554.28 & 294.59 & 149.64 & 79.24 \\
\hline & 17 & 22.272 & 325.77 & 228.15 & 150.76 & 97.07 & 537.30 & 327.38 & 189.42 & 109.16 & 713.13 & 399.78 & 213.59 & 116.15 \\
\hline
\end{tabular}

\section{Effect of height of chimney}

The effect of height of chimney was investigated by considering four different heights $(H=100,200,300$ and 400) of chimney. The tip deflection of chimney increases with increase in chimney elevation. Generally, it is seen that the variation of tangential moments in higher elevation chimneys of 300 and $400 \mathrm{~m}\left(H / D_{\mathrm{b}}=17\right.$ and soil type $\left.\mathrm{S} 1\right)$ is high when compared to that in chimneys of 200 and $100 \mathrm{~m}$. The variation of radial moment is significant in chimneys of all elevations. The variation in base moment of chimney is more than $75 \%$ even with the effect of interaction with supporting rock base as compared to fixed base.

\section{Simplified equivalent fixed base models for SSI}

There is a high demand for developing simplified SSI models used to determine the actual response of chimneys under the flexibility of soil without conducting the rigorous and time-consuming numerical analysis. From the extensive parametric study, simplified equivalent fixed base models were developed using multi-linear regression analysis which will be helpful for practical purposes to evaluate wind response of chimneys considering detrimental effects of SSI. From the extensive SSI analysis, it is found that the base moment of the chimney with soil as flexible base is less than that in the conventional analysis in which fixity at the base of chimney is assumed. Therefore, the reduction of base moment of chimney due to SSI is deemed to be conservative and could be ignored in the design procedure contributing to safer design. However, amplification of tip deflection of chimney and maximum tangential and radial moment in the chimney shell due to SSI have detrimental effects on performance and safety of chimney-foundation system and must be taken into account in any design procedure. The ratio of maximum elastic response of chimney with flexible base to fixed base was derived. This ratio is called modification factor $(X)$.

$\frac{\Delta^{\prime}}{\Delta}=X_{(\text {tip deflection })}$

where $\Delta^{\prime}$ is the tip deflection of chimney with flexible base and $\Delta$ is the tip deflection of chimney with fixed base.

$$
\begin{aligned}
X_{(\text {tip deflection })=} & 7.195-0.001 \times H+0.029 \times K_{\mathrm{CS}} \\
& -1.24 \times K_{\mathrm{RS}}-4.296 \times\left(\gamma_{\mathrm{c}} / \gamma_{\mathrm{s}}\right) \\
& +4.97 \times 10-9 \times M_{(\text {base })},
\end{aligned}
$$

where $H$ is the height of chimney $(\mathrm{m}), \gamma_{\mathrm{c}}$ is the density of material of chimney-foundation system $\left(\mathrm{kN} / \mathrm{m}^{3}\right), \gamma_{\mathrm{s}}$ is the density of soil stratum $\left(\mathrm{kN} / \mathrm{m}^{3}\right), M_{\text {(base) }}$ is the base moment of chimney with fixed base $(\mathrm{kNm})$ and $K_{\mathrm{CS}}$ is the relative stiffness of chimney.

$K_{\mathrm{CS}}$ given below is the modified formulation given by Potts and Addenbrooke (1997):

$K_{\mathrm{CS}}=\frac{\mathrm{EI}}{E_{\mathrm{s}}\left(\frac{D_{\mathrm{b}}}{2}\right)^{4}}$,

where EI is the bending stiffness of chimney, $D_{\mathrm{b}}$ is the diameter at the bottom of the chimney in the plane of deformation and $K_{\mathrm{RS}}$ is the relative stiffness of raft; $K_{\mathrm{RS}}$ given below is the modified formulation given by Fraser and Wardle (1976): 
Fig. 10 Contour of radial moment $(\mathrm{kNm})$ of $200 \mathrm{~m}$ chimney $\left(H / D_{\mathrm{b}}=7\right.$ and $\left.D_{\mathrm{o}} / t=22.5\right)$ resting on soil types a S1, b S2, c S3, d S4 and e fixed base
A
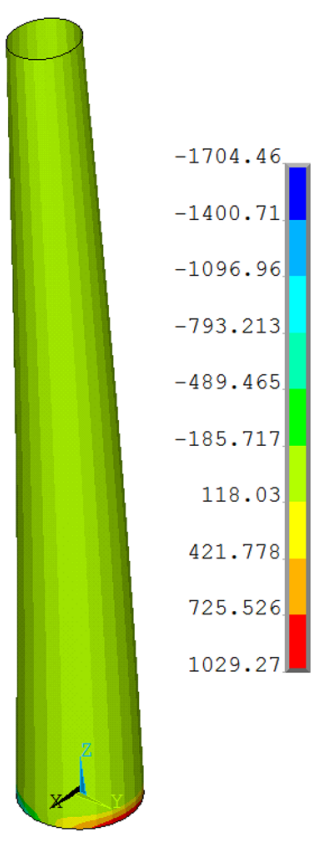

D

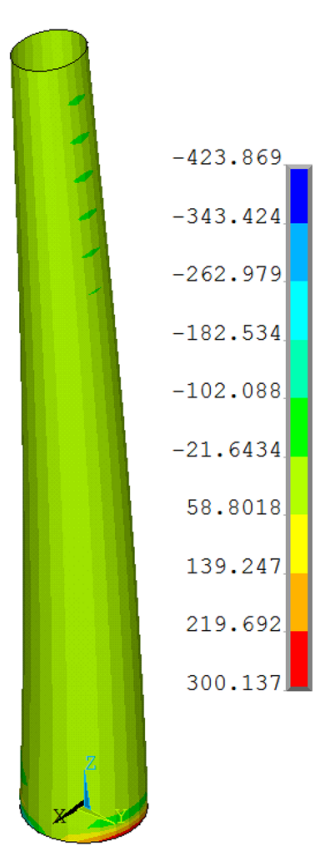

$K_{\mathrm{RS}}=4 E_{\mathrm{R}}\left(1-v_{\mathrm{S}}^{2}\right) t_{\mathrm{R}}^{3} / 3 E_{\mathrm{S}}\left(1-v_{\mathrm{R}}^{2}\right)\left(D_{\mathrm{o}}-D_{\mathrm{i}}\right)^{3}$,

where $E_{\mathrm{R}}$ is the Young's modulus of raft, $E_{\mathrm{S}}$ is the Young's modulus of soil, $v_{\mathrm{R}}$ is the Poisson's ratio of raft, $v_{\mathrm{S}}$ is the Poisson's ratio of soil, $t_{\mathrm{R}}$ is the thickness of the raft, $D_{\mathrm{o}}$ is the outer diameter of annular raft and $D_{\mathrm{i}}$ is the inner diameter of annular raft.

It is seen that the practical range of relative stiffness of chimney is $1<K_{\mathrm{CS}}<65$, whereas that of raft is
B

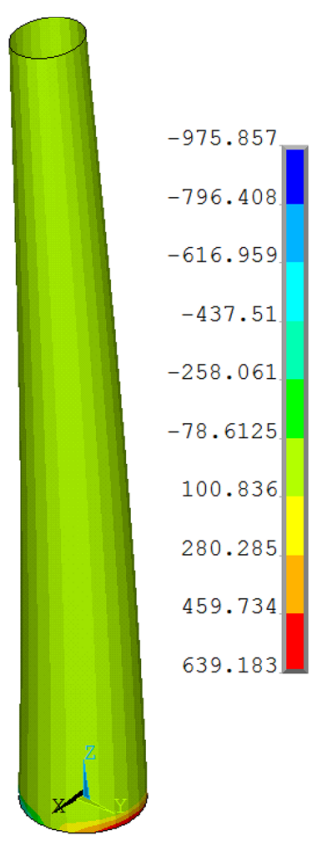

C

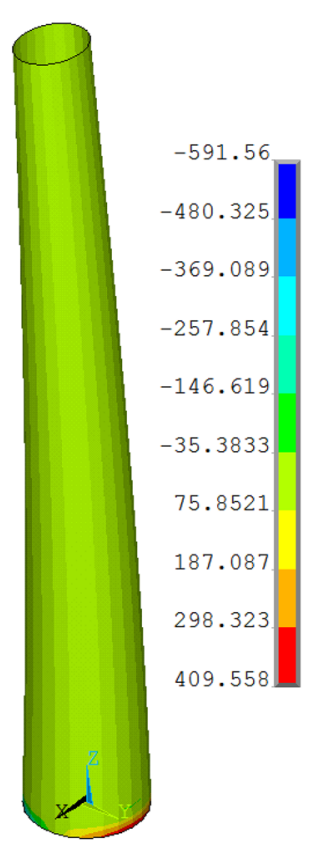

E

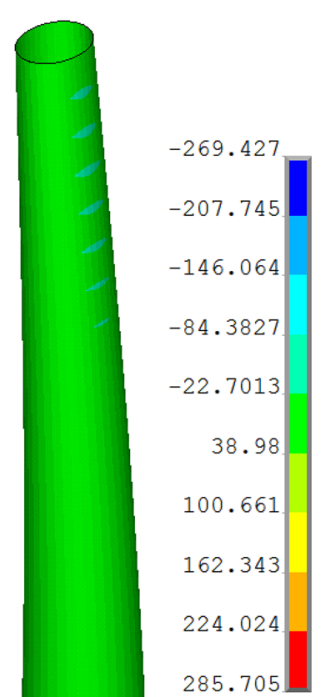

$0.001<K_{\mathrm{RS}}<0.5$. The upper limit of $K_{\mathrm{CS}}$ represents chimney resting on loose sand, whereas the lower limit of $K_{\mathrm{CS}}$ represents chimney resting on rock. Hence the lower limit of $K_{\mathrm{CS}}$ points out little interaction effect with soil. The lower limit of $K_{\mathrm{RS}}$ represents a flexible raft resting on rock and the upper limit of $K_{\mathrm{RS}}$ represents a virtually rigid foundation resting on loose sand.

The modification factor for tangential moment in chimney $\left(X_{\left(M_{\text {tchimney }}\right)}\right)$ is given as following: 

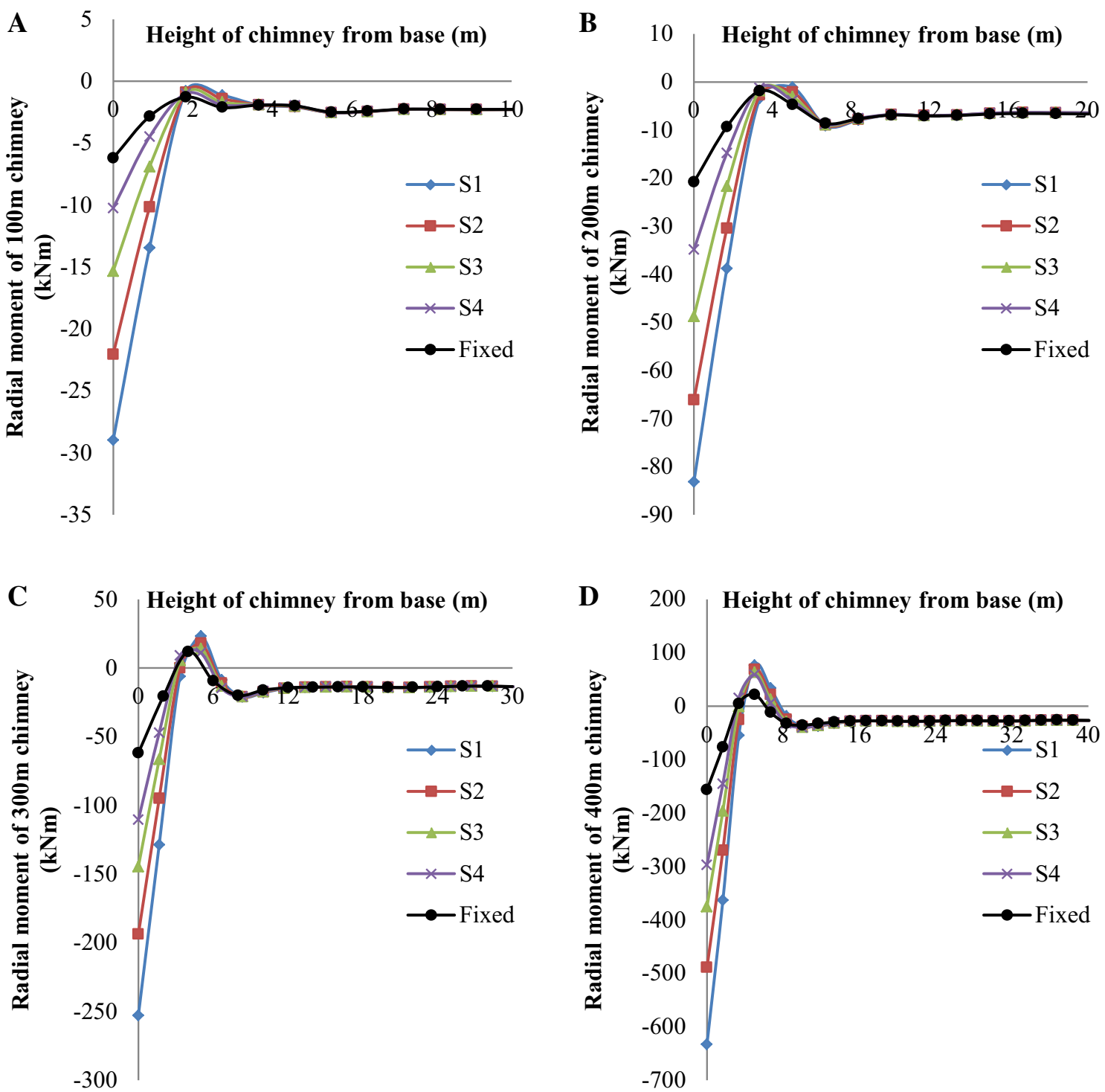

Fig. 11 Radial moment of a 100 m, b 200 m, c 300 m, d 400 m chimney $\left(H / D_{\mathrm{b}}=17\right)$ with flexible and rigid base

$\frac{M_{\mathrm{t}(\text { chimney })}^{\prime}}{M_{\mathrm{t}(\text { chimney })}}=X_{\left(M_{\mathrm{t} \text { chimney }}\right)}$.

where $M_{\mathrm{t}}^{\prime}$ (chimney) is the maximum tangential moment in chimney with flexible base and $M_{\mathrm{t}}$ (chimney) is the maximum tangential moment in chimney with fixed base.

The equation of modification factor for tangential moment in chimney is given as following:

$$
\begin{aligned}
X_{\left(M_{\text {t chimney }}\right)=} & -10.502+0.005 \times H+0.087 \times K_{\mathrm{CS}} \\
& -15.544 \times K_{\mathrm{RS}}+9.344 \times\left(\gamma_{\mathrm{c}} / \gamma_{\mathrm{s}}\right) \\
& -1.03 \times 10^{-7} \times M_{(\text {base })}
\end{aligned}
$$

The modification factor for radial moment in chimney $\left(X_{\left(M_{\text {rchimney }}\right)}\right)$ is given as following:
$\frac{M_{\mathrm{r}(\text { chimney })}^{\prime}}{M_{\mathrm{r}(\text { chimney })}}=X_{\left(M_{\text {r chimney }}\right)}$,

where $M_{\mathrm{r} \text { (chimney) }}^{\prime}$ is the maximum radial moment in chimney with flexible base and $M_{\mathrm{r} \text { (chimney) }}$ is the maximum radial moment in chimney with fixed base.

The equation of modification factor for radial moment in chimney is given as following:

$$
\begin{aligned}
X_{\left(M_{\text {rchimney }}\right)=} & -16.201-0.004 \times H+0.118 \times K_{\mathrm{CS}} \\
& -21.281 \times K_{\mathrm{RS}}+15.904 \times\left(\gamma_{\mathrm{c}} / \gamma_{\mathrm{s}}\right) \\
& -5.91 \times 10^{-8} \times M_{(\text {base })}
\end{aligned}
$$

Equations (15), (19) and (21) are valid only for $0.01<K_{\mathrm{RS}}<0.456$. The effect of SSI is found significant in this range of relative raft stiffness. 
Table 7 Variation of radial moment of chimney due to chimney-piled raft-soil interaction

\begin{tabular}{|c|c|c|c|c|c|c|c|c|c|c|c|c|c|c|}
\hline \multirow[t]{3}{*}{$H(\mathrm{~m})$} & \multirow[t]{3}{*}{$H / D_{\mathrm{b}}$} & \multirow{3}{*}{$\begin{array}{l}\text { Radial } \\
\text { moment of } \\
\text { chimney with } \\
\text { fixed base } \\
(\mathrm{kNm})\end{array}$} & \multicolumn{12}{|c|}{ Percentage variation of radial moment of chimney due to chimney-piled raft-soil interaction (\%) } \\
\hline & & & \multicolumn{4}{|c|}{$D_{\mathrm{o}} / t=12.5$} & \multicolumn{4}{|c|}{$D_{\mathrm{o}} / t=17.5$} & \multicolumn{4}{|c|}{$D_{\mathrm{o}} / t=22.5$} \\
\hline & & & S1 & $\mathrm{S} 2$ & S3 & S4 & S1 & S2 & S3 & S4 & S1 & S2 & S3 & S4 \\
\hline \multirow[t]{3}{*}{100} & 7 & 78.37 & 206.30 & 128.19 & 57.29 & 10.43 & 372.91 & 193.33 & 75.19 & 15.86 & 490.47 & 230.62 & 86.59 & 20.25 \\
\hline & 12 & 8.75 & 488.95 & 370.65 & 222.86 & 99.58 & 867.05 & 569.79 & 277.63 & 106.67 & 1367.97 & 780.89 & 315.82 & 113.34 \\
\hline & 17 & 6.20 & 367.28 & 255.41 & 147.16 & 65.14 & 661.40 & 382.00 & 177.69 & 69.85 & 901.82 & 451.73 & 185.98 & 72.43 \\
\hline \multirow[t]{3}{*}{200} & 7 & 269.43 & 248.96 & 166.92 & 95.33 & 50.15 & 413.34 & 228.56 & 111.05 & 54.56 & 532.56 & 262.13 & 119.47 & 57.24 \\
\hline & 12 & 29.70 & 536.84 & 346.06 & 190.66 & 97.93 & 851.11 & 464.89 & 219.52 & 106.52 & 1055.53 & 528.73 & 235.67 & 113.13 \\
\hline & 17 & 20.80 & 299.69 & 217.96 & 134.37 & 67.78 & 559.58 & 337.88 & 173.60 & 80.47 & 765.29 & 417.43 & 199.38 & 89.14 \\
\hline \multirow[t]{3}{*}{300} & 7 & 779.29 & 257.57 & 171.17 & 107.48 & 68.54 & 389.10 & 221.84 & 124.27 & 74.18 & 492.31 & 255.91 & 135.70 & 77.87 \\
\hline & 12 & 85.71 & 423.30 & 281.37 & 174.74 & 109.29 & 647.37 & 373.15 & 203.60 & 117.81 & 815.01 & 431.55 & 220.27 & 123.41 \\
\hline & 17 & 61.85 & 308.83 & 213.31 & 133.69 & 78.62 & 519.09 & 307.83 & 166.73 & 88.45 & 691.55 & 374.50 & 187.54 & 94.35 \\
\hline \multirow[t]{3}{*}{400} & 7 & 1427.90 & 228.87 & 156.15 & 106.78 & 76.59 & 327.07 & 197.53 & 122.56 & 81.90 & 407.16 & 228.10 & 133.06 & 85.08 \\
\hline & 12 & 320.69 & 337.84 & 227.73 & 147.66 & 96.39 & 504.07 & 300.39 & 173.25 & 104.06 & 657.80 & 358.01 & 190.79 & 109.85 \\
\hline & 17 & 156.34 & 304.84 & 212.87 & 140.22 & 90.10 & 501.14 & 304.42 & 175.52 & 100.91 & 663.91 & 371.08 & 197.44 & 107.07 \\
\hline
\end{tabular}

Table 8 Variation of base moment of chimney due to chimney-piled raft-soil interaction

\begin{tabular}{|c|c|c|c|c|c|c|c|c|c|c|c|c|c|c|}
\hline \multirow[t]{3}{*}{$H(\mathrm{~m})$} & \multirow[t]{3}{*}{$H / D_{\mathrm{b}}$} & \multirow{3}{*}{$\begin{array}{l}\text { Base } \\
\text { moment of } \\
\text { chimney } \\
\text { with fixed } \\
\text { base } \\
(\mathrm{kNm})\end{array}$} & \multicolumn{12}{|c|}{ Percentage variation of base moment of chimney due to chimney-piled raft-soil interaction $(\%)$} \\
\hline & & & \multicolumn{4}{|c|}{$D_{\mathrm{o}} / t=12.5$} & \multicolumn{4}{|c|}{$D_{\mathrm{o}} / t=17.5$} & \multicolumn{4}{|c|}{$D_{\mathrm{o}} / t=22.5$} \\
\hline & & & S1 & S2 & S3 & S4 & S1 & S2 & S3 & S4 & S1 & S2 & S3 & S4 \\
\hline \multirow[t]{3}{*}{100} & 7 & 731,018 & -99.39 & -98.20 & -95.45 & -90.96 & -98.92 & -97.16 & -93.39 & -86.90 & -98.52 & -96.23 & -91.25 & -82.79 \\
\hline & 12 & 79,420 & -99.05 & -97.30 & -93.43 & -87.80 & -98.43 & -95.97 & -91.07 & -83.63 & -97.54 & -94.30 & -88.12 & -77.56 \\
\hline & 17 & 62,045 & -87.78 & -85.84 & -83.79 & -80.41 & -78.47 & -78.30 & -77.18 & -72.52 & -72.23 & -72.10 & -70.92 & -64.53 \\
\hline \multirow[t]{3}{*}{200} & 7 & $5,498,938$ & -99.88 & -99.45 & -98.41 & -96.45 & -99.79 & -99.10 & -97.54 & -94.48 & -99.69 & -98.75 & -96.62 & -92.38 \\
\hline & 12 & 629,786 & -99.58 & -98.63 & -96.52 & -93.02 & -99.25 & -97.83 & -94.96 & -89.95 & -98.99 & -97.20 & -93.53 & -87.20 \\
\hline & 17 & 485,981 & -99.28 & -97.86 & -94.40 & -88.63 & -98.69 & -96.48 & -91.64 & -83.48 & -98.20 & -95.36 & -89.17 & -78.88 \\
\hline \multirow[t]{3}{*}{300} & 7 & $17,553,686$ & -99.93 & -99.61 & -98.78 & -97.32 & -99.88 & -99.37 & -98.20 & -96.14 & -99.81 & -99.14 & -97.60 & -94.94 \\
\hline & 12 & $2,124,915$ & -99.84 & -99.30 & -97.97 & -95.62 & -99.69 & -98.80 & -96.92 & -93.59 & -99.54 & -98.38 & -95.98 & -91.77 \\
\hline & 17 & $1,638,583$ & -99.68 & -98.86 & -96.83 & -93.33 & -99.38 & -98.06 & -95.21 & -90.33 & -99.11 & -97.36 & -93.72 & -87.51 \\
\hline \multirow[t]{3}{*}{400} & 7 & $39,879,581$ & -99.97 & -99.80 & -99.31 & -98.44 & -99.95 & -99.68 & -98.98 & -97.76 & -99.93 & -99.56 & -98.66 & -97.07 \\
\hline & 12 & $7,841,886$ & -99.91 & -99.57 & -98.66 & -97.01 & -99.84 & -99.28 & -98.00 & -95.72 & -99.74 & -98.99 & -97.31 & -94.37 \\
\hline & 17 & $3,958,270$ & -99.84 & -99.31 & -97.96 & -95.53 & -99.68 & -98.78 & -96.82 & -93.44 & -99.51 & -98.32 & -95.83 & -91.55 \\
\hline
\end{tabular}

\section{Conclusions}

The effect of SSI was investigated for reinforced concrete chimneys with piled raft foundation founded on four different types of soil subjected to wind loads. Piled raft foundations having different thickness of raft, different chimney elevations and different slenderness ratio of chimney were selected for the parametric study. Threedimensional finite element analysis of integrated soilfoundation-chimney system was carried out. 180 numbers of finite element models were generated. The responses of chimney in terms of lateral deflection, tangential and radial bending moment and base moment were evaluated for the chimney-piled raft-soil system and compared with chimneys of fixed base. The percentage variation was computed for maximum values of moments in chimney obtained through SSI analysis and from fixed base analysis of chimney.

The responses in chimney such as lateral deflection, tangential moment and radial moment increases with increase in the flexibility of soil whereas the base moment of chimney increases with increase in stiffness of the soil. It is 
Fig. 12 a Tangential moment, b radial moment of $100 \mathrm{~m}$ chimney $\left(H / D_{\mathrm{b}}=12\right)$ with different $D_{\mathrm{o}} / t$ ratios of raft

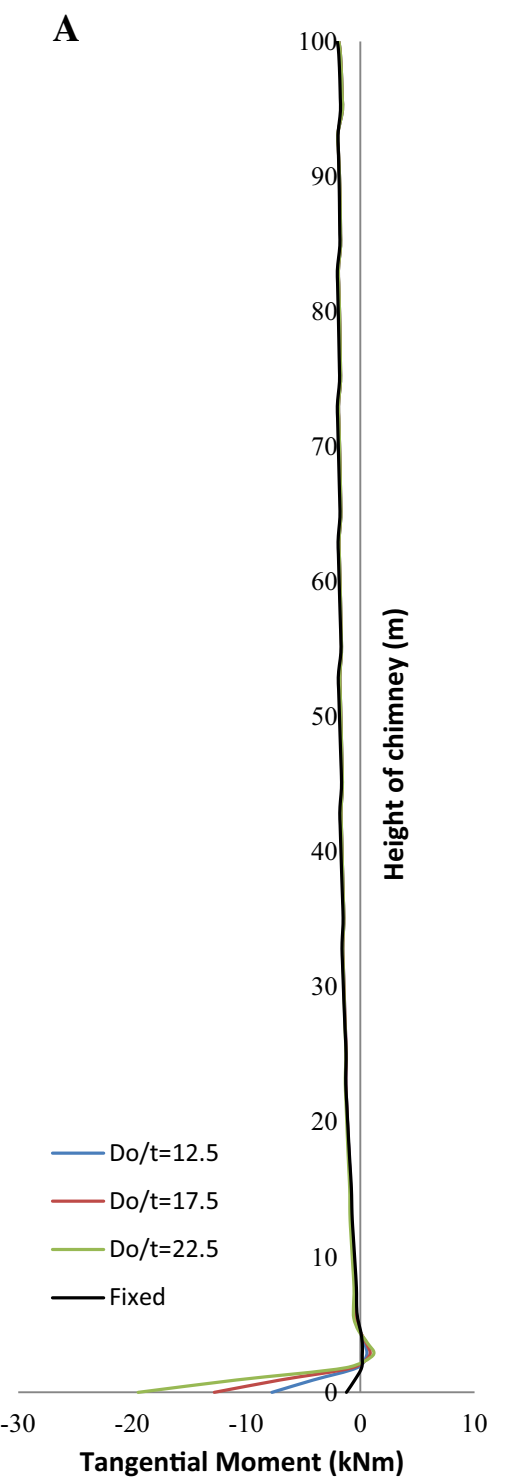

also found that the different responses in chimney are increased drastically with decrease in the thickness of raft of piled raft foundation. The variations of tangential and radial moments are higher in slender chimneys. A higher variation of tangential moments is seen in the chimneys of higher elevations whereas the variation of radial moments is significant for all chimneys under consideration.

The following general observations are drawn from the SSI analysis of chimney with piled raft foundation:

- The base moment of chimney is reduced more than $75 \%$ from that of chimney with fixed base due to the effect of SSI.

- For stocky chimneys, the maximum tangential moment is found at the base due to SSI whereas it occurs at a height of $H / 3 \mathrm{~m}$ from the top of the chimney for fixed base.
- The effect of SSI is significant only up to a height of $H$ / 40 from the base of the chimney in radial moment variation and $H / 20$ from the base in the case of tangential moment variation.

- The maximum tangential moment in stocky chimney founded on loose sand is increased by 2.5 times of that in chimney with fixed base whereas for slender chimneys it is increased up to eight times of that with fixed base.

- The variation in maximum tangential moment of chimney is double for a chimney with thin raft as compared to that with thick raft when founded on loose sand. Similar variation occurs in radial moment also.

It is concluded that the estimation of the response of slender chimneys due to SSI is very important. Construction of chimneys even with piled raft foundation having 
skin friction piles in loose sand is not recommended. The effect of SSI is predominant at the base of chimney. Hence, the response variation at base for a distance of at least $1 / 40$ th of the height of chimney should be considered for safe design. The present SSI study would be helpful to the design engineers for the optimum selection of geometrical parameters of chimney and foundation.

Open Access This article is distributed under the terms of the Creative Commons Attribution 4.0 International License (http:// creativecommons.org/licenses/by/4.0/), which permits unrestricted use, distribution, and reproduction in any medium, provided you give appropriate credit to the original author(s) and the source, provide a link to the Creative Commons license, and indicate if changes were made.

\section{References}

ACI (307-2008) (2008) Code requirements for reinforced concrete chimneys (ACI 307-08) and commentary. American Concrete Institute, Farmington Hills

Arunachalam S, Govindaraju SP, Lakshmanan N, Appa Rao TVSR (2001) Across-wind aerodynamic parameters of tall chimneys with circular cross section-a new empirical model. Eng Struct 23:502-520

Arya AS, Paul DK (1977) Earthquake response of tall chimneys. In: Proceedings of the sixth world conference, Delhi, pp 1247-1259

Bowles JE (1997) Foundation analysis and design. McGraw-Hill, Singapore

Brown PT (1969) Numerical analysis of uniformly loaded circular rafts on deep elastic foundations. Geotechnique 19:399-404

Cakir T (2013) Evaluation of the effect of earthquake frequency content on seismic behaviour of cantilever retaining wall including soil-structure interaction. Soil Dyn Earthq Eng 45:96-111

Chaudhary MTA (2007) FEM modelling of a large piled raft for settlement control in weak rock. Eng Struct 29:2901-2907

Chowdhury I, Dasgupta SP (2009) Dynamics of structure and foundation-a unified approach. CRC Press, The Netherlands

Chu KH, Afandi OF (1966) Analysis of circular and annular slabs for chimney foundations. J ACI 63:1425-1447

CICIND (2001) Model code for concrete chimneys, Part A. In: The Shell, 2nd edn (revision 1)

Davenport AG (1967) Gust loading factors. J Struct Eng ASCE 93:1295-1313

Davenport AG (1995) How can we simplify and generalize wind loads. J Wind Eng Ind Aerodyn 54(55):657-669

Dewaikar DM, Patil PA (2006) Analysis of a laterally loaded pile in cohesionless soil under static and cyclic loading. Ind Geotech J 36(2):181-189

Fang HY (1991) Foundation engineering handbook. Van Nostrand Reinhold, New York

Fraser RA, Wardle LJ (1976) Numerical analysis of rectangular rafts on layered foundations. Geotechnique 26(4):613-630

Ghosh S, Wilson EL (1969) Dynamic stress analysis of axi-symmetric structures under arbitrary loading. In: Report No. EERC 69-10. University of California, Berkeley

IS: 11089-1984 (reaffirmed 2002) Code of practice for design and construction of ring foundation. Bureau of Indian Standards, New Delhi
IS: 4998(Part 1)-1992 (reaffirmed 2003) Criteria for the design of reinforced concrete chimneys. Bureau of Indian Standards, New Delhi

IS: 875(Part 3)-1987 (reaffirmed 2003) Code of practice for design loads (other than earthquake) for building and structures. Bureau of Indian Standards, New Delhi

Jayalekshmi BR, Menon D, Prasad AM (2011) Effect of soilstructure interaction on along-wind response of tall chimneys. IACMAG 2:846-851

Koten HV (2005) Wind actions. In: Zurich (ed) The CICIND chimney book: industrial chimneys of concrete or steel. CICIND, Zurich, pp 99-114

Kwok KCS, Melbourne WH (1981) Wind induced lock in excitation of tall structures. J Struct Eng ASCE 107(1):57-72

Manohar SN (1985) Tall chimneys-design and construction. Tata MacGraw-Hill, New Delhi

Mehta D, Gandhi NJ (2008) Time study response of tall chimneys under the effect of soil structure interaction and long period earthquake impulse. In: The 14th world conference on earthquake engineering, China

Melbourne WH (1997) Predicting the cross-wind response of masts and structural members. J Wind Eng Ind Aerodyn 69(71):91-103

Melerski ES (1990) Simple computer analysis of circular rafts under various axisymmetric loading and elastic foundation conditions. Proc Inst Civ Eng Part 2(89):407-431

Menon D, Rao PS (1997a) Estimation of along-wind moments in RC chimneys. Eng Struct 19(1):71-78

Menon D, Rao PS (1997b) Uncertainties in codal recommendations for across-wind analysis of RC chimneys. J Wind Eng Ind Aerodyn 72:455-468

NEHRP (1994) Recommended provisions for seismic regulations of new buildings. Part 1-Provisions. FEMA 222A

Potts D, Addenbrooke T (1997) A structure's influence on tunnellinginduced ground movements. Proc Inst Civ Eng Geotech Eng 125:109-125

Pour NS, Chowdhury I (2008) Dynamic soil structure interaction analysis of tall multi-flue chimneys under aerodynamic and seismic force. In: The 12th international conference on IACMAG, India, pp 2696-2703

Rajasankar J, Iyer NR, Swamy BY, Goplalakrishnan N, Chellapandi P (2007) SSI analysis of a massive concrete structure based on a novel convolution/deconvolution technique. Sadhana 32:215-234

Sáez E, Caballero FL, Razavi AMF (2011) Effect of the inelastic dynamic soil-structure interaction on the seismic vulnerability assessment. Struct Saf 33:51-63

Simiu E (1976) Equivalent static wind loads for tall building design. J Struct Eng ASCE 102:719-737

Solari G (1982) Along-wind response estimation: closed form solution. J Struct Eng ASCE 108:225-234

Tabatabaiefar HR, Massumi A (2010) A simplified method to determine seismic responses of reinforced concrete moment resisting building frames under influence of soil-structure interaction. Soil Dyn Earthq Eng 30:1259-1267

Turner T (2005) Industrial chimney foundations. In: Zurich (ed) The CICIND chimney book: industrial chimneys of concrete or steel. CICIND, Zurich, pp 79-98

Vickery BJ, Clark AW (1972) Lift or across-wind response of tapered stacks. J Struct Eng ASCE 98(ST 1):1-20

Wolf JP (1985) Dynamic soil-structure interaction. Prentice-Hall, New York 